\title{
Occurrence of ozone anomalies over cloudy areas in TOMS version-7 level-2 data
}

\author{
X. Liu ${ }^{1, *}$, M. J. Newchurch ${ }^{1}$, and J. H. Kim ${ }^{2}$ \\ ${ }^{1}$ Atmospheric Science Department, University of Alabama in Huntsville, Huntsville, Alabama, USA \\ ${ }^{2}$ Atmospheric Science Department, Pusan National University, Korea \\ *now at: Smithsonian Astrophysical Observatory, Cambridge, MA, USA
}

Received: 8 November 2002 - Published in Atmos. Chem. Phys. Discuss.: 13 January 2003

Revised: 9 April 2003 - Accepted: 21 July 2003 - Published: 1 August 2003

\begin{abstract}
This study investigates anomalous ozone distributions over cloudy areas in Nimbus-7 (N7) and Earth-Probe (EP) TOMS version-7 data and analyzes the causes for ozone anomaly formation. A $5^{\circ}$-longitude by $5^{\circ}$-latitude region is defined to contain a Positive Ozone Anomaly (POA) or Negative Ozone Anomaly (NOA) if the correlation coefficient between total ozone and reflectivity is $\geq 0.5$ or $\leq-0.5$. The average fractions of ozone anomalies among all cloud fields are $31.8 \pm 7.7 \%$ and $35.8 \pm 7.7 \%$ in the N7 and EP TOMS data, respectively. Some ozone anomalies are caused by ozone retrieval errors, and others are caused by actual geophysical phenomena. Large cloud-height errors are found in the TOMS version-7 algorithm in comparison to the Temperature Humidity Infrared Radiometer (THIR) cloud data. On average, cloud-top pressures are overestimated by $\sim 200 \mathrm{hPa}$ (THIR cloud-top pressure $\leq 200 \mathrm{hPa}$ ) for high-altitude clouds and underestimated by $\sim 150 \mathrm{hPa}$ for low-altitude clouds (THIR cloud-top pressure $\geq 750 \mathrm{hPa}$ ). Most tropical NOAs result from negative errors induced by large cloud-height errors, and most tropical POAs are caused by positive errors due to intra-cloud ozone absorption enhancement. However, positive and negative errors offset each other, reducing the ozone anomaly occurrence in TOMS data. Large ozone/reflectivity slopes for mid-latitude POAs show seasonal variation consistent with total ozone fluctuation, indicating that they result mainly from synoptic and planetary wave disturbances. POAs with an occurrence fraction of 30-60\% occur in regions of marine stratocumulus off the west coast of South Africa and off the west coast of South America. Both fractions and ozone/reflectivity slopes of these POAs show seasonal variations consistent with that in the tropospheric ozone. About half the ozone/reflectivity slope can be explained by ozone retrieval errors over clear and cloudy areas. The remaining slope may result from there being more ozone production because of rich ozone precur-
\end{abstract}

Correspondence to: X. Liu (xliu@cfa.harvard.edu) sors and higher photolysis rates over high-frequency, lowaltitude clouds than in clear areas. Ozone anomalies due to ozone retrieval errors have important implications in TOMS applications such as tropospheric ozone derivation and analysis of ozone seasonal variation.

\section{Introduction}

Thompson et al. (1993) and Hudson et al. (1995) noticed the unrealistically high degree of statistical correlation between TOMS version-6 Total Ozone Column (TOC) and reflectivity in regions of marine stratocumulus. This correlation is caused mainly by oversimplifying that CloudTop Pressure (CTP) is dependent only on latitude but not on cloud types, cloud thickness, and regions (Thompson et al., 1993): $P_{\text {cloud }}(\mathrm{atm})=0.3+0.15[1-\cos (2 \times$ latitude $)]$. The TOMS Version-7 (V7) algorithm uses the monthly mean CTPs from International Satellite Cloud Climatology Project (ISCCP) cloud data and a more accurate model for partial clouds (McPeters et al., 1996). These improvements largely reduce the overestimate of TOC in these marine stratocumulus cloudy regions (Hsu et al., 1997; McPeters and Labow, 1996). Newchurch et al. (2001) found that CTPs are largely overestimated by $\sim 200 \mathrm{hPa}$ for tropical highreflectivity clouds in TOMS V7 data. Correcting incorrect CTPs leads to significant cloudy TOC excess of 10-15 Dobson Units (DU) $\left(1 \mathrm{DU}=2.69 \cdot 10^{16}\right.$ molecules $\left.\mathrm{cm}^{-2}\right)$ compared to nearby clear areas. We have discovered a peculiar distribution of $40 \mathrm{DU}$ more TOC over high cloudy regions in the northern central United States on 29 June 1989, where there is a well-studied strong convective thunderstorm (Poulida et al., 1996). The actual cloud height is $\sim 11-14 \mathrm{~km}$, much higher than the assumed cloud height of $\sim 6 \mathrm{~km}$, and correcting cloud-height errors will increase the cloudy/clear TOC difference. Either ozone retrieval errors other than incorrect cloud heights or actual geophysical phenomena (i.e. 
(a) Total Ozone Distribution (DU)

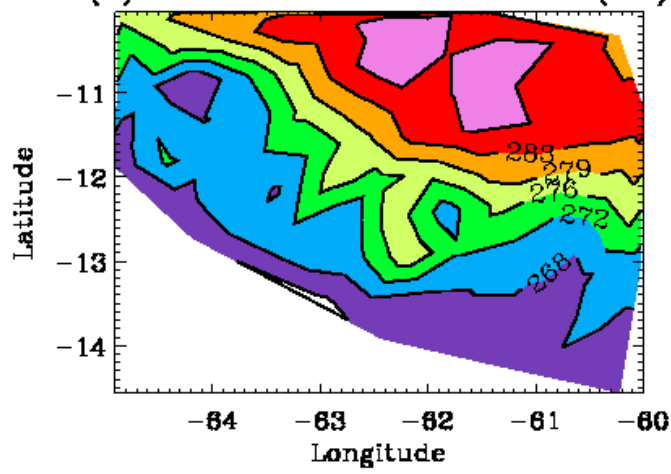

(b) Reflectivity Distribution (\%)

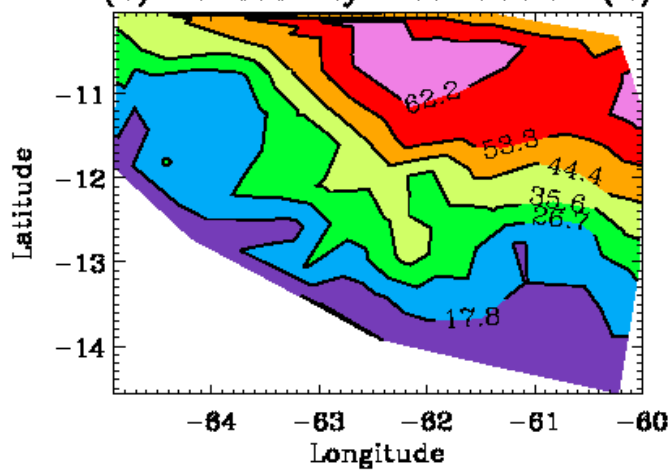

(c) Total Ozone vs. Reflectivity

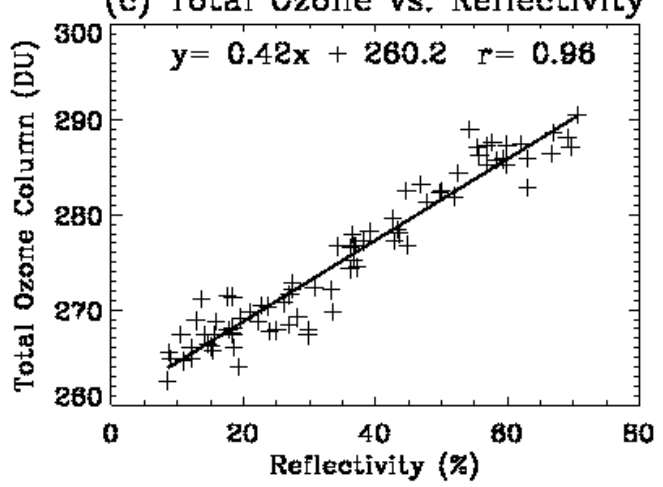

(a) Total Ozone Distribution (DU)

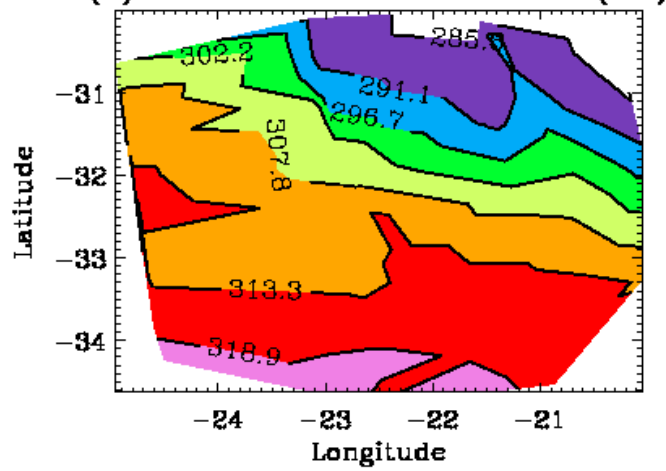

(b) Reflectivity Distribution (\%)

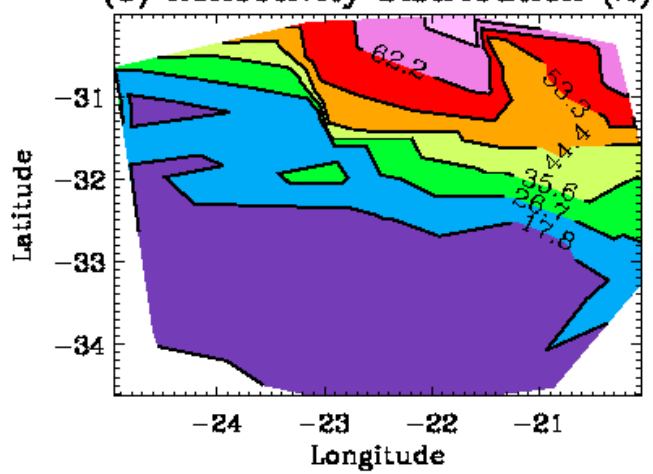

(c) Total Ozone vs, Reflectivity

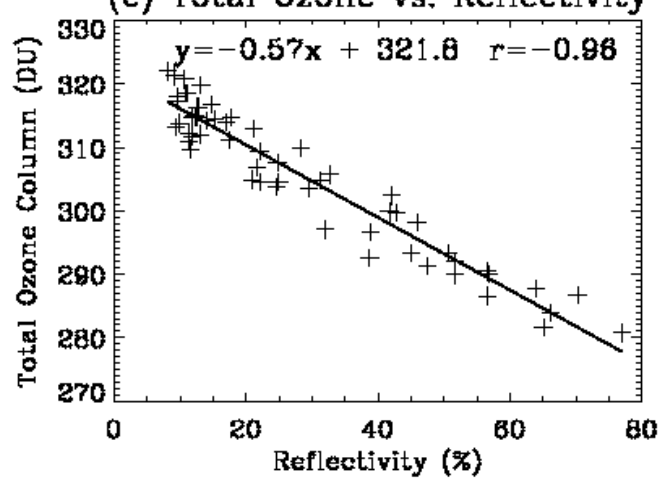

Fig. 1. Anomalous ozone distribution over cloudy areas located in South America on 1 January 1980 (left), and in the south Atlantic Ocean on 15 July 1980 (right). (a) Distribution of total ozone. (b) Distribution of reflectivity. (c) Relationship between total ozone and reflectivity.

real) or both cause this observed cloudy ozone column excess.

Ozone retrieval errors associated with clouds not only affect ozone retrieval accuracy in cloudy scenes, but also propagate to affect the accuracy of the TOMS level-3 data and zonal mean TOC. Furthermore, these ozone retrieval errors will affect tropospheric ozone derivations using cloudy/clear difference techniques such as the Convective-Cloud Differential (CCD) (Ziemke et al., 1998) and the Clear-Cloudy Pairs (CCP) (Newchurch et al., 2002) methods. To investigate these ozone retrieval errors, we need to separate them from the effects of actual geophysical phenomena. In this study, we investigate the frequency of occurrence of Ozone Anomalies (OAs) over cloudy areas in TOMS V7 level-2 data, and analyze geophysical phenomena or ozone retrieval errors behind anomalous ozone distribution. Section 2 of this paper introduces the data and methodology. We present the OA occurrence in Sect. 3. Section 4 discusses the essential causes of OA formation. Section 5 discusses the effects of OAs on TOMS applications and Sect. 6 summarizes this study. 


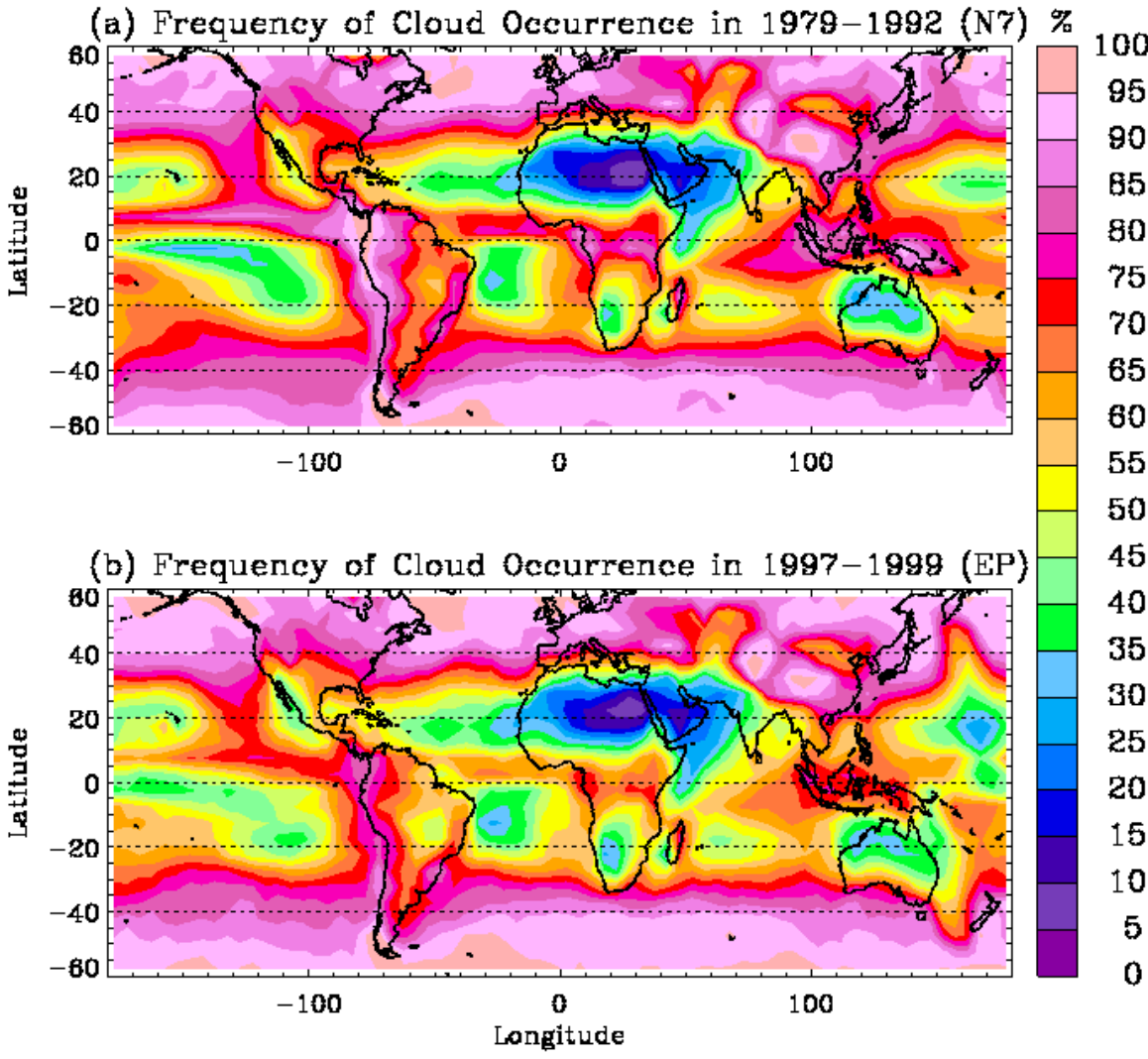

Fig. 2. Average frequency distribution of cloud fields during the 1979-1992 N7 TOMS period (a) and the 19971999 EP TOMS period (b).

\section{Data and methodology}

We use the global daily high-resolution TOMS level-2 data from Nimbus-7 (N7) TOMS during 1979-1992 and from Earth-Probe (EP) TOMS during 1997-1999. The spatial resolution at the nadir view is about $50 \times 50 \mathrm{~km}^{2}$ for a N7 TOMS pixel and is $25 \times 25 \mathrm{~km}^{2} / 39 \times 39 \mathrm{~km}^{2}$ for an EP TOMS pixel before/after December 1997 (McPeters et al., 1996, 1998), larger at larger view zenith angle. On average, there are about 70 pixels in a $5^{\circ} \times 5^{\circ}$ area. To focus on cloudy effects, we correct ozone retrieval errors due to both sun glint and aerosols using the Dave reflectivity correction code (personal communication with C. G. Wellemeyer, 1999). The effects of ozone correction are apparent in regions of sun glint, dust, and biomass burning. The corrected ozone column is typically $2 \sim 8 \mathrm{DU}$ for sun glint, $2 \sim 10 \mathrm{DU}$ for biomass burning aerosols, and 2 20 DU for desert dust, consistent with the results of McPeters et al. (1996) and Torres and Bhartia (1999). To avoid problems due to snow, ice, and polar stratospheric clouds at high-latitudes (McPeters et al., 1996), we study only regions between $60^{\circ} \mathrm{S}$ and $60^{\circ} \mathrm{N}$.

Figure 1 shows two examples of anomalous ozone distribution over cloudy areas, one with more TOC over cloudy areas (left) and the other with less TOC over cloudy areas (right). The TOC distribution is high-positively or negatively correlated with the TOMS-measured 380-nm reflectivity dis- tribution. Such anomalous ozone distribution is not unusual in the TOMS V7 data. There are 2183 such cases with correlation coefficients $\geq 0.9$ or $\leq-0.9$ in 1980 . We calculate the spatial correlation coefficients and linear regression slopes between the daily TOC and 380-nm (in N7)/or 360$\mathrm{nm}$ (in EP) reflectivity (simplified as ozone/reflectivity slope or slope) in $5^{\circ}$-longitude by $5^{\circ}$-latitude areas, where there are at least 20 measurements and the reflectivity range is $\geq 30 \%$. Such a $5^{\circ} \times 5^{\circ}$ grid can be considered to be a cloud field that contains scenes of different cloudiness and might include clear, partly cloudy, and overcast scenes. Figure 2 shows the spatial frequency distribution of such cloud fields averaged over the N7 and EP TOMS periods, respectively. During the N7 TOMS period, most of the regions contain cloud fields with a frequency greater than $60 \%$. Regions with frequencies less than $40 \%$ include subtropical semi-permanent areas and desert areas such as North Africa, the Arabian Peninsula, and northwestern Australia. The frequency distribution of cloud fields during the EP TOMS period is similar except that the frequency in the tropics is smaller by $\sim 15 \%$. This is mainly because the N7 satellite (with an altitude of $800 \mathrm{~km}$ ) is higher than the EP satellite, therefore providing more spatial coverage in the tropics. The elevation of EP from $500 \mathrm{~km}$ to $740 \mathrm{~km}$ at the end of 1997 increases the tropical frequency by $12 \%$ but is still $10 \%$ less than the average N7 frequency. 

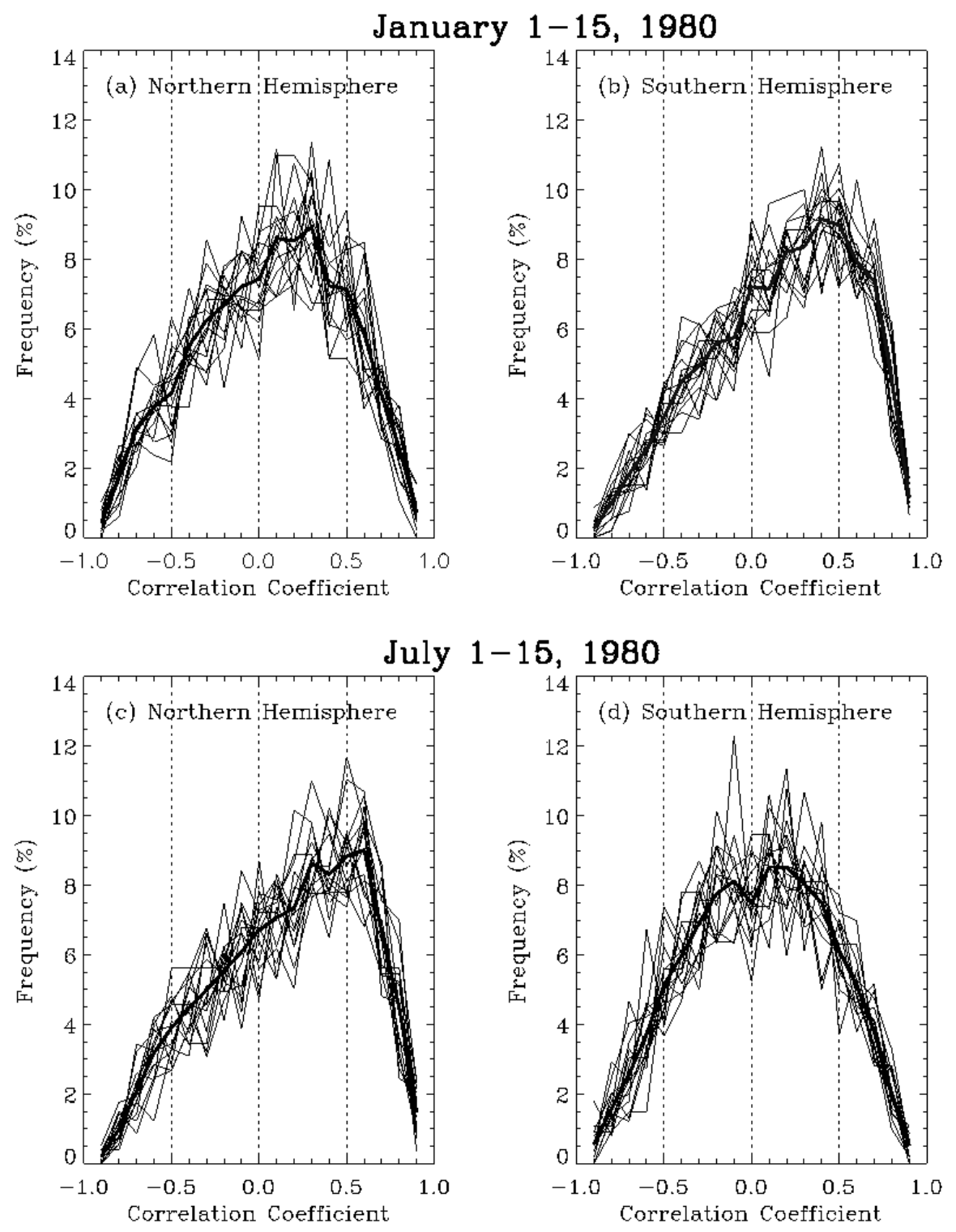

Fig. 3. Frequency of correlation coefficients (in each bin of 0.1 ) between the TOMS total ozone and the TOMS 380-nm reflectivity in $5^{\circ}$-longitude $\times 5^{\circ}$-latitude areas in the Northern and Southern Hemispheres during 1-15 January 1980 and 1-15 July 1980 .

The N7/EP difference is small at mid-latitudes because both N7 and EP TOMS instruments provide full spatial coverage.

Figure 3 shows the daily frequency of correlation coefficients in both hemispheres in January and July 1980, respectively. Each thin curve represents the frequency distribution for one day, and the daily curves are very similar for each day. In both hemispheres, these correlation coefficients peak around zero in the winter (In this paper, a season refers to both boreal and austral ones unless specified such as austral winter) but shift to the right in the summer mostly due to the summer increase in cloud occurrence (Stowe et al., 1989). There is a significant fraction of large negative or positive correlation coefficients. Because reflectivity is usually related to cloudiness, the larger correlation coefficients and slopes usually indicate larger cloudy/clear TOC differences. To characterize the frequency of occurrence of anomalous ozone distributions over cloudy areas such as the cases shown in Fig. 1, the intermediate values \pm 0.5 , between which includes approximately $68 \%$ ( $1 \delta$ for normal distribution) of the correlation coefficients, are selected as criteria. If a correlation coefficient is $\geq 0.5$ or $\leq-0.5$, we define it as a Positive Ozone Anomaly (POA) or a Negative Ozone Anomaly (NOA), respectively. Correspondingly, the slope for a NOA or POA will be negative and positive, respectively. We find all the OAs from the N7 and EP TOMS data and build yearly OA databases. 

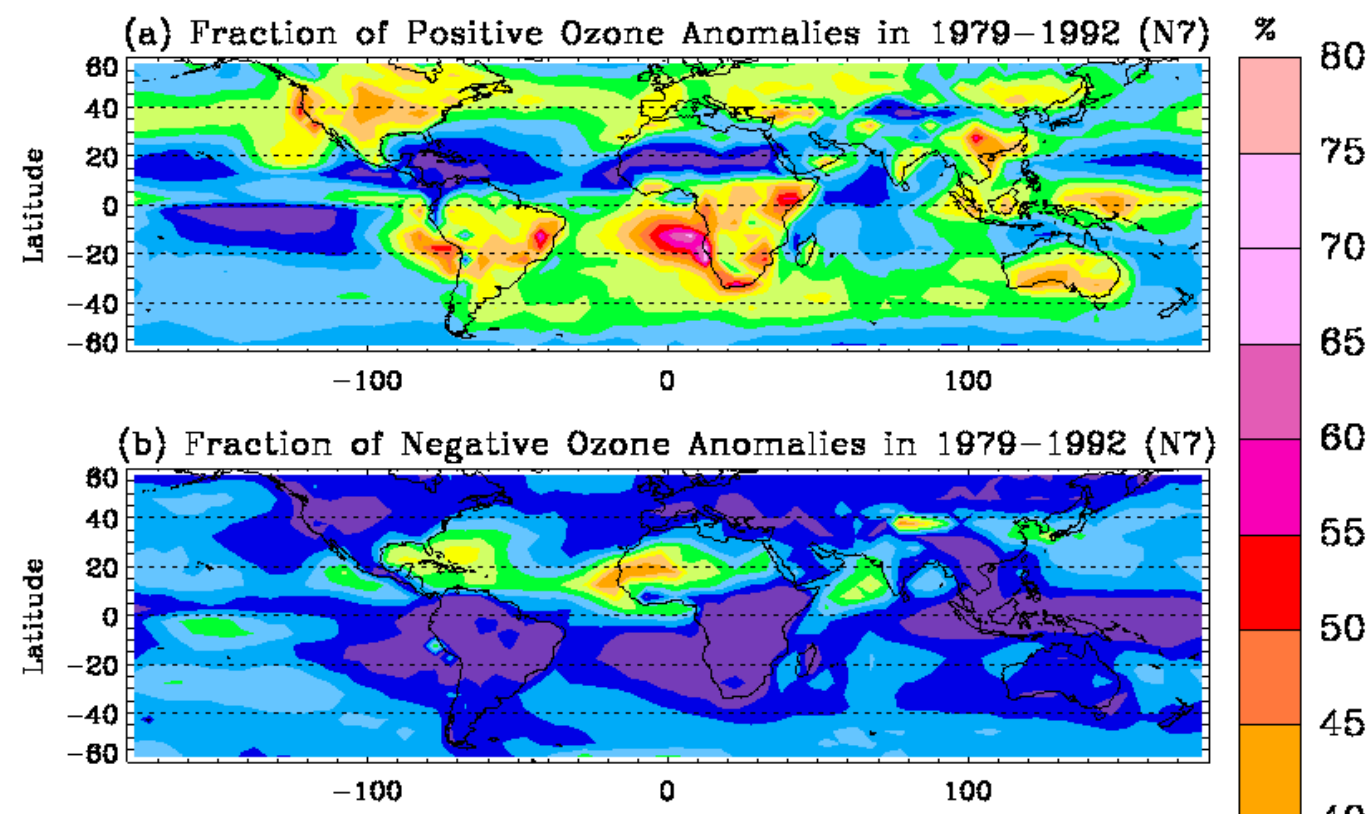

60

(c) Fraction of Positive Ozone Anomalies in 1997-1999 (EP)

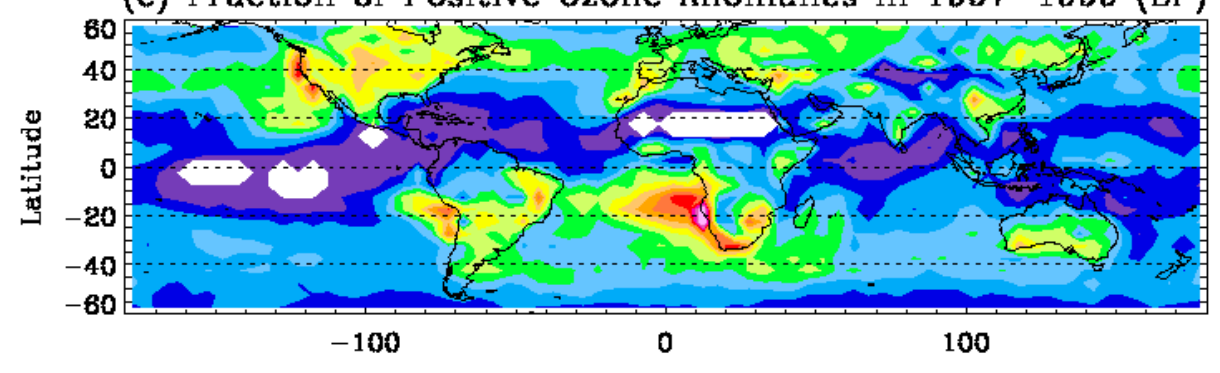

55

50

45

40

35

30

25

20

(d) Fraction of Negative Ozone Anomalies in 1997-1999 (EP)

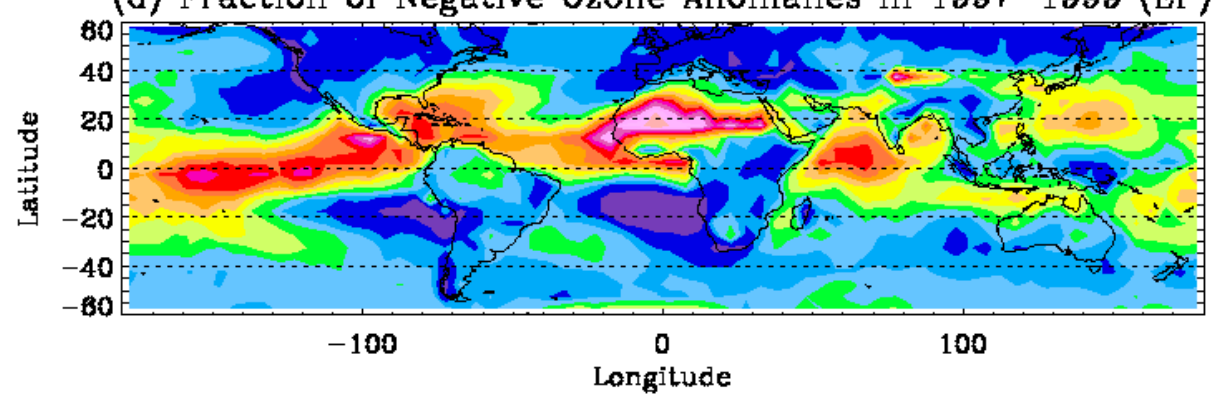

15

10

5

Fig. 4. Ozone anomalies in 1979-1992 N7 TOMS data and 1997-1999 EP TOMS data. (a) Average fractional distribution of positive ozone anomalies in N7 TOMS data from 1979 to 1992. (b) Same as (a) except for negative ozone anomalies. (c) and (d) Same as (a) and (b) except in 1997-1999 EP TOMS data.

\section{Occurrence of ozone anomalies}

Figures $4 \mathrm{a}$ and $\mathrm{b}$ show the spatial mean fraction distributions of POAs and NOAs in the 14-year N7 TOMS period. We define the fraction for a $5^{\circ} \times 5^{\circ}$ grid as the portion of cloud fields with POAs or NOAs. The average fraction of occurrence of OAs is $31.8 \pm 7.7 \%$ ( 1 standard deviation). About $18 \%$ and $59 \%$ of OAs occur over both land and ocean, almost proportional to the land and ocean area coverage. A signifi- cant portion of OAs ( $\sim 22 \%)$ occurs in coastal areas. Cuevas et al. (2001) found persistent total ozone difference between continents and oceans mainly caused by truncation of lower tropospheric ozone due to topography and probably the presence of more UV-absorbing aerosols over land. The sea-land total ozone difference caused by these mechanisms and by sea-land ozone retrieval efficiency difference due to different sea and land surface reflectivity, when correlated with cloud distributions, will increase the possibility of ozone anomaly 


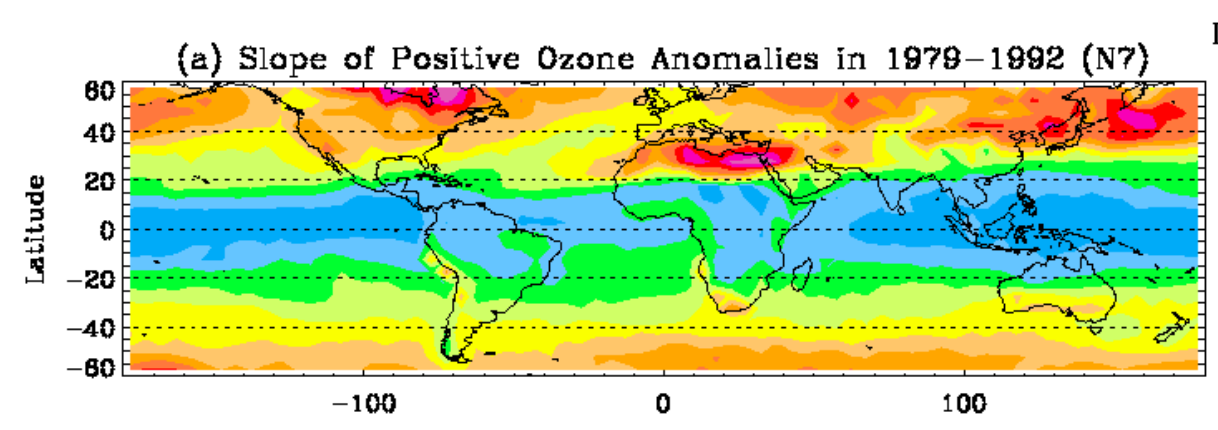

$\mathrm{DU} / 100 \%$
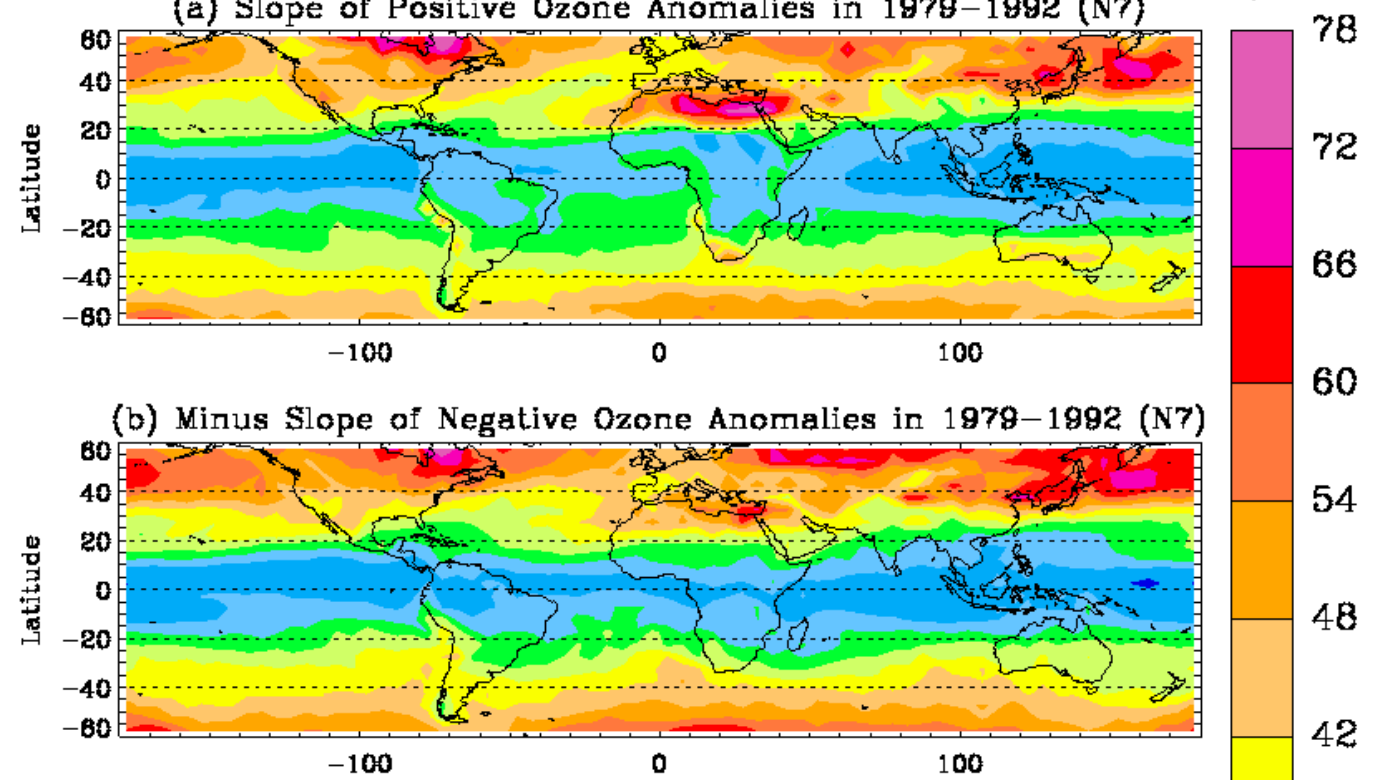

60

54

48

(c) Slope of Positive Ozone Anomalies in 1997-1999 (EP)

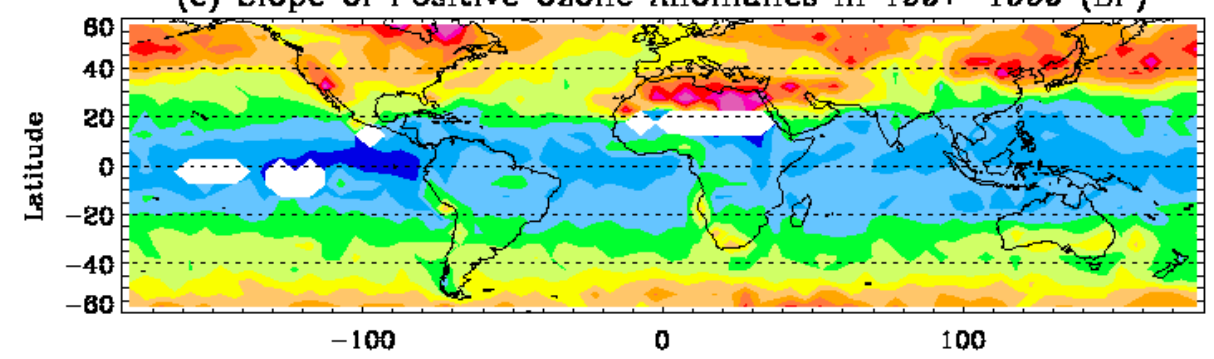

(d) Minus Slope of Negative Ozone Anomalies in 1997-1999 (EP)
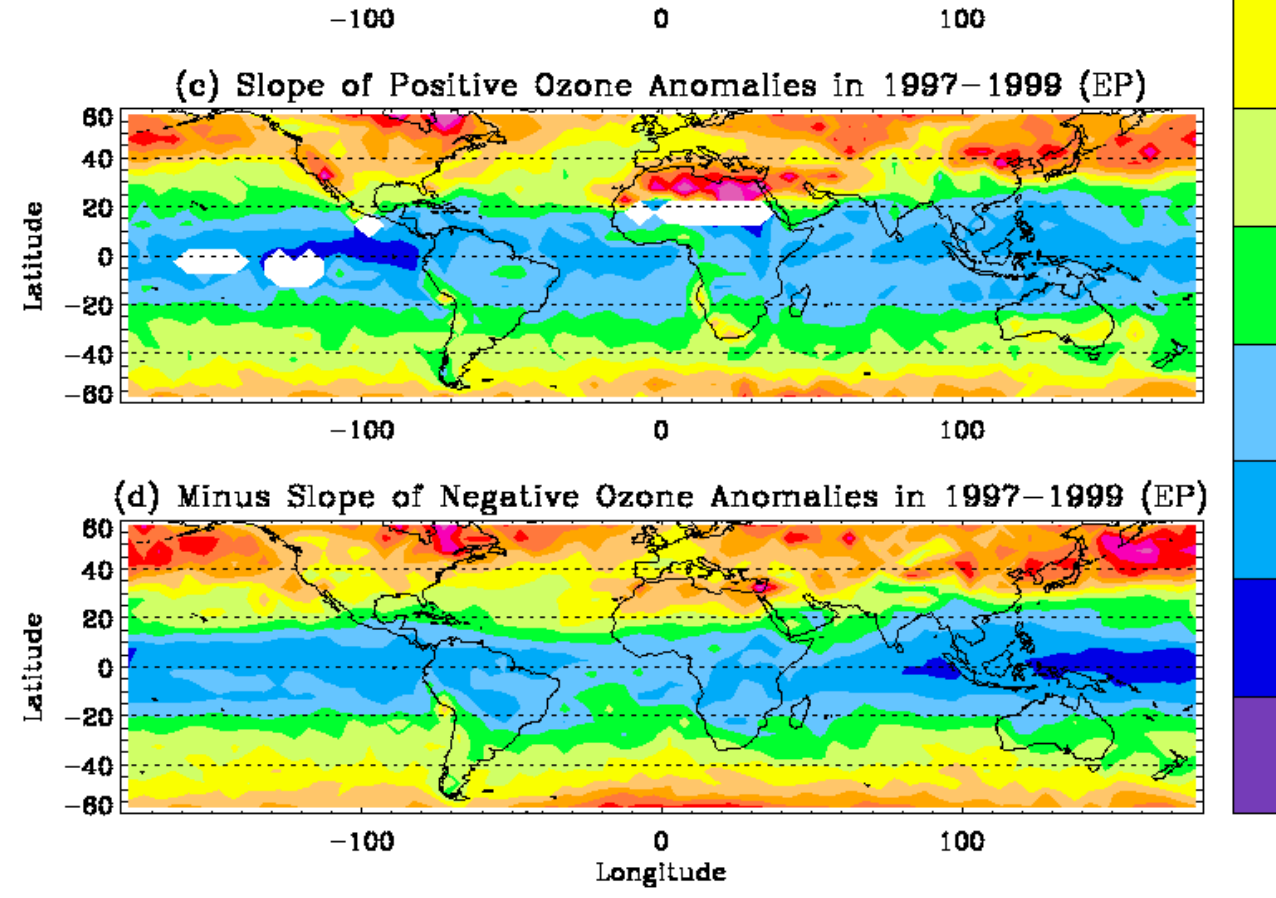

42

36

30

24

18

12

6

0

Fig. 5. Same as Fig. 4 except for the magnitudes of linear regression slopes between ozone and reflectivity for ozone anomalies. The slopes are negative for negative ozone anomalies and positive for positive ozone anomalies.

occurrence. The average fraction for POAs is $21.1 \pm 10.0 \%$, almost twice that of NOAs, which is $10.6 \pm 6.3 \%$. Some regions are dominated with a high fraction of POAs and NOAs. Two extensive regions dominated by POAs, with fractions $>40 \%$, are located over the eastern Atlantic Ocean off the west coast of South Africa (WCSAF) and over the eastern Pacific Ocean off the west coast of South America (WCSAM). These are regions of frequent marine stratocumulus (Rossow and Schiffer, 1991; Thompson et al., 1993). Other regions with POAs of fractions $>40 \%$ include the United States, central China, southern Australia, and tropical convective cloudy areas (Ramanathan et al., 1989; Stowe et al., 1989; Wang et al., 1996) such as central America, central Africa, and the western Pacific Ocean. Mid-latitude regions are extensively associated with high dense POAs with a fraction of $15-40 \%$. Areas of NOAs with a fraction $>25 \%$ occur in mountainous regions in northwestern China, North Africa, the Atlantic Ocean (from the southeastern United States to 
(a) Dec. $1981-$ Feb. 1982



(b) Dec. $1982-F e b .1983$

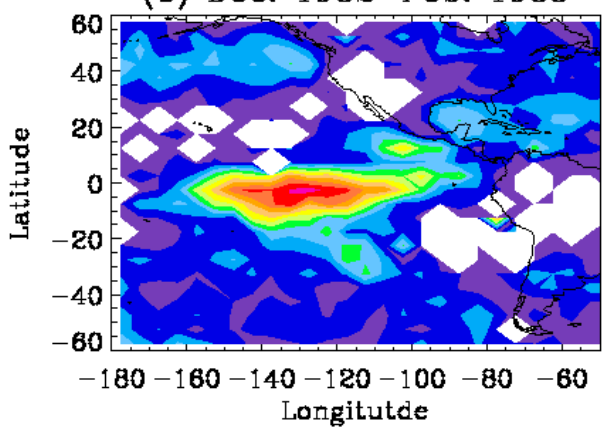

(c) Dec, $1996-$ Feb. 1997



(d) Dec. $1997-F e b .1998$



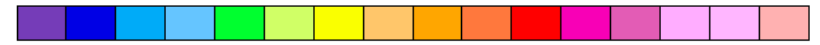

$\begin{array}{llllllllllllllllll}0 & 6 & 12 & 18 & 24 & 30 & 36 & 42 & 48 & 54 & 60 & 66 & 72 & 78 & 84 & 90 & 96 & \%\end{array}$

Fig. 6. Effects of the 1982-1983 and 1997-1998 El Niño events on ozone anomaly distribution. (a) Fraction distribution of negative ozone anomalies in non-El Niño period from December 1981 to February 1982. (b) Same as (a) except in El Niño period from December 1982 to February 1983. (c) and (d) same as (a) and (b) except for the 1997 1998 El Niño event.
North Africa), and the Indian Ocean.

Figures $4 \mathrm{c}$ and d show similar distributions of POAs and NOAs except for the three-year EP TOMS period. The average fraction of occurrence of OAs is $35.8 \pm 9.7 \%$. We can see that there are more NOAs in the EP TOMS data than in the N7 TOMS data everywhere. Especially in tropical areas, there are very few POAs in tropical convective cloudy regions, but there is a high fraction ( $\geq 40 \%$ ) of NOAs distributed in the intertropical convergence zone regions. On average, there are more NOAs $(20.5 \pm 12.7 \%)$ than POAs $(15.3 \pm 9.1 \%)$. At mid-latitudes, the overall fractions of OAs are similar between the N7 and EP TOMS data. The larger fraction of OAs by $4 \%$ in the EP TOMS data originates mainly from many more tropical NOAs. Despite the N7/EP TOMS difference in the distribution of POAs and NOAs, the overall geographical locations of OAs are similar in both TOMS data. Ziemke et al. (2000) and Newchurch et al. (2001) noticed the N7/EP TOMS bias that the cloudy/clear TOC difference in N7 TOMS data is $~ 5 \mathrm{DU}$ larger than that in EP TOMS data. The smaller cloudy/clear TOC difference in EP TOMS data leads to the larger fraction of NOAs, especially in tropical areas. The reason for this EP/N7 bias is not yet resolved, but it is most probably due to nonlinearity calibration errors in EP or N7 or both (Newchurch et al., 2001). The linear treatment of nonlinear calibration produces errors in high reflectivity pixels (larger digital counts) relative to low reflectivity scenes (lower digital counts).

Figure 5 shows the spatial distribution of the average ozone/reflectivity slope (magnitude) of POAs and NOAs. Unlike the fraction of OA occurrence, the magnitude of the slope does not depend greatly on the sign of an anomaly, the type of surface (land/sea), the fraction of occurrence, or different satellites (N7 vs. EP). Instead, it is mainly a function of latitude, increasing from about $12-30$ DU/100\% reflectivity (simplified as DU/100\%) in tropical areas to about 40$80 \mathrm{DU} / 100 \%$ at mid-latitudes.

The above features of fraction and slope distributions of POAs and NOAs are very consistent in every year in the N7 or EP TOMS data, except in El Niño years. In the N7 TOMS or EP TOMS period, the annual fraction variation is within $3 \%$ and the slope variation is within $5 \mathrm{DU} / 100 \%$. Although El Niño events do not present significant changes to the annual average fraction, they do produce significant regional effects. Figure 6 compares the average fractions of NOAs during the non-El Niño periods (from December 1981 to February 1982 and from December 1996 to February 1997) and the El Niño periods (from December 1982 to February 1983 and from December 1997 to February 1998). The most significant change is a $\sim 40 \%$ increase in the fraction of NOAs over the tropical eastern Pacific Ocean. This change in the fraction of OAs begins significantly in Novem- 


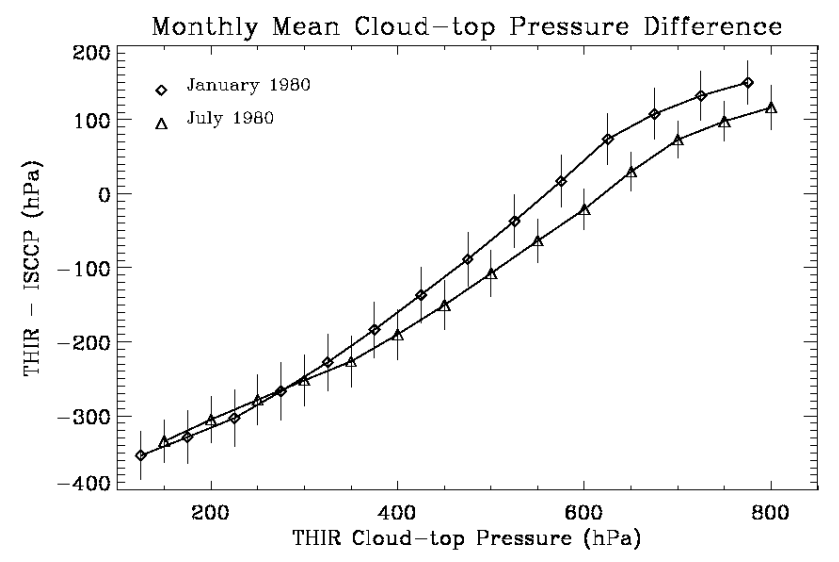

Fig. 7. Monthly average pressure difference between THIR and ISCCP cloud-top pressure as a function of THIR cloud-top pressure in January and July 1980. The vertical bars are the \pm 1 standard errors. The $x$-axis values are the same for January and July, but the $x$-axis values for July are shifted by $25 \mathrm{hPa}$ to avoid overlapping.

ber (1982-1983) or July (1997-1998), peaks from November through February, and disappears in July, time periods consistent with the duration of these two El Niño events. The effects of the 1986-1987 and 1991-1992 El Niño events on OAs are much smaller.

\section{Causes of ozone anomaly occurrence over cloudy ar- eas}

\subsection{Effects of incorrect cloud-top heights}

Newchurch et al. (2001) showed an example in the tropics in which large ozone retrieval errors occur in TOMS data over cloudy areas because of incorrect cloud heights, and correcting these errors greatly increases the slope and correlation coefficient between ozone and reflectivity. This example shows that incorrect cloud heights affect OA occurrence. We use Temperature Humidity Infrared Radiometer (THIR) cloud measurements on board the N7 satellite to analyze errors in assumed monthly mean CTPs from ISCCP cloud data. THIR CTPs are derived from radiances measured at $11.5 \mu \mathrm{m}$ along with the NCEP/NCAR (National Centers for Environmental Prediction/National Center for Atmospheric Research) $2.5^{\circ} \times 2.5^{\circ} 6$-h grids of temperature profiles (Stowe et al., 1989). The six-year (1979-1984) THIR CTPs are collocated with TOMS measurements and archived in TOMS data products. The major sources of potential errors in the derived CTPs would be in the accuracy of NCEP/NCAR temperature profiles and the collocation of THIR and TOMS pixels over broken cloudy conditions (Newchurch et al., 2001). Figure 7 shows the monthly average CTP difference between THIR and ISCCP between $60^{\circ} \mathrm{S}$ and $60^{\circ} \mathrm{N}$ as a function of THIR CTP in January and July 1980, respectively. Each of the
14 point represents the average CTP pressure difference for clouds with THIR CTPs within a 50-hPa layer ranging from $800 \mathrm{hPa}$ to $100 \mathrm{hPa}$. On average, the assumed CTP is overestimated for high clouds and underestimated for low clouds. The CTP difference ranges from $-300 \mathrm{hPa}$ for high clouds (THIR CTP $\leq 200 \mathrm{hPa}$ ) to $150 \mathrm{hPa}$ for low clouds (THIR CTP $\geq 750 \mathrm{hPa}$ ). We have noted a $60-80-\mathrm{hPa}$ underestimation of THIR CTPs for high-altitude clouds (Newchurch et al., 2001). Accounting for errors in THIR CTPs, the CTPs assumed in TOMS data are overestimated by $\sim 200 \mathrm{hPa}$ for high-altitude clouds. To evaluate the effects of significant cloud height errors on OA occurrence, we correct ozone retrieval errors caused by incorrect cloud heights in TOMS data during 1979-1983 using the $\Delta \mathrm{P}$ correction method introduced in Newchurch et al. (2001), and then compare the $\mathrm{OA}$ occurrence before and after the $\Delta \mathrm{P}$ correction. The $\Delta \mathrm{P}$ correction method corrects three types of cloud-heightrelated errors using pre-calculated look up tables of these errors: radiation interpolation error, ozone retrieval error above clouds, and ozone retrieval error below clouds. Correcting incorrect cloud heights helps us understand other causes of OA formation.

Figures $8 \mathrm{a}$ and $\mathrm{b}$ show fraction distributions of POAs and NOAs similar to Figs. $4 \mathrm{a}$ and $\mathrm{b}$ except after the $\Delta \mathrm{P}$ correction during 1979-1983. POAs with such high fractions as $50-70 \%$ occur extensively in the tropical and subtropical convective cloudy areas and the fraction of POAs dramatically increases by $20-50 \%$ relative to the fraction before the $\Delta \mathrm{P}$ correction. The $\Delta \mathrm{P}$ correction eliminates most tropical NOAs seen in Fig. $4 \mathrm{~b}$ because the cloud-top heights of tropical high-altitude and high-reflectivity clouds are significantly underestimated, and the correction adds more ozone below clouds. Therefore, tropical NOAs are mainly caused by incorrect cloud heights assumed in TOMS V7 algorithm. The $\triangle \mathrm{P}$ correction decreases the fraction of POAs by 5$10 \%$ over WCSAF and WCSAM because the assumed CTHs are sometimes overestimated for low marine stratocumulus clouds. The fractions of POAs and NOAs in mid-latitude cloudy regions change, usually within $\pm 10 \%$, because of the $\Delta \mathrm{P}$ correction. After the $\Delta \mathrm{P}$ correction, most of the regions show much fewer NOAs than POAs. The main region with more NOAs than POAs occurs in the Southern Hemisphere at $60^{\circ} \mathrm{S}-50^{\circ} \mathrm{S}$. Another region with more NOAs lies in North Africa, but this region has very few cloud fields. Figures $8 \mathrm{c}$ and $\mathrm{d}$ show the average ozone/reflectivity slopes for POAs and NOAs after the $\triangle \mathrm{P}$ correction during 1979-1983. Compared to the large changes shown in the average spatial fraction distribution, the changes in slope are relatively small. The slope changes for both POAs and NOAs are usually within $\pm 10 \mathrm{DU} / 100 \%$ at all regions.

Although there is a large difference in the fraction of NOAs before the $\Delta \mathrm{P}$ correction between $\mathrm{El}$ Niño and non-El Niño periods over the eastern Pacific Ocean, there are almost no NOAs for both periods after the $\Delta \mathrm{P}$ correction, as shown in Figs. 9a and $\mathrm{b}$. The shift in the convection pattern due 

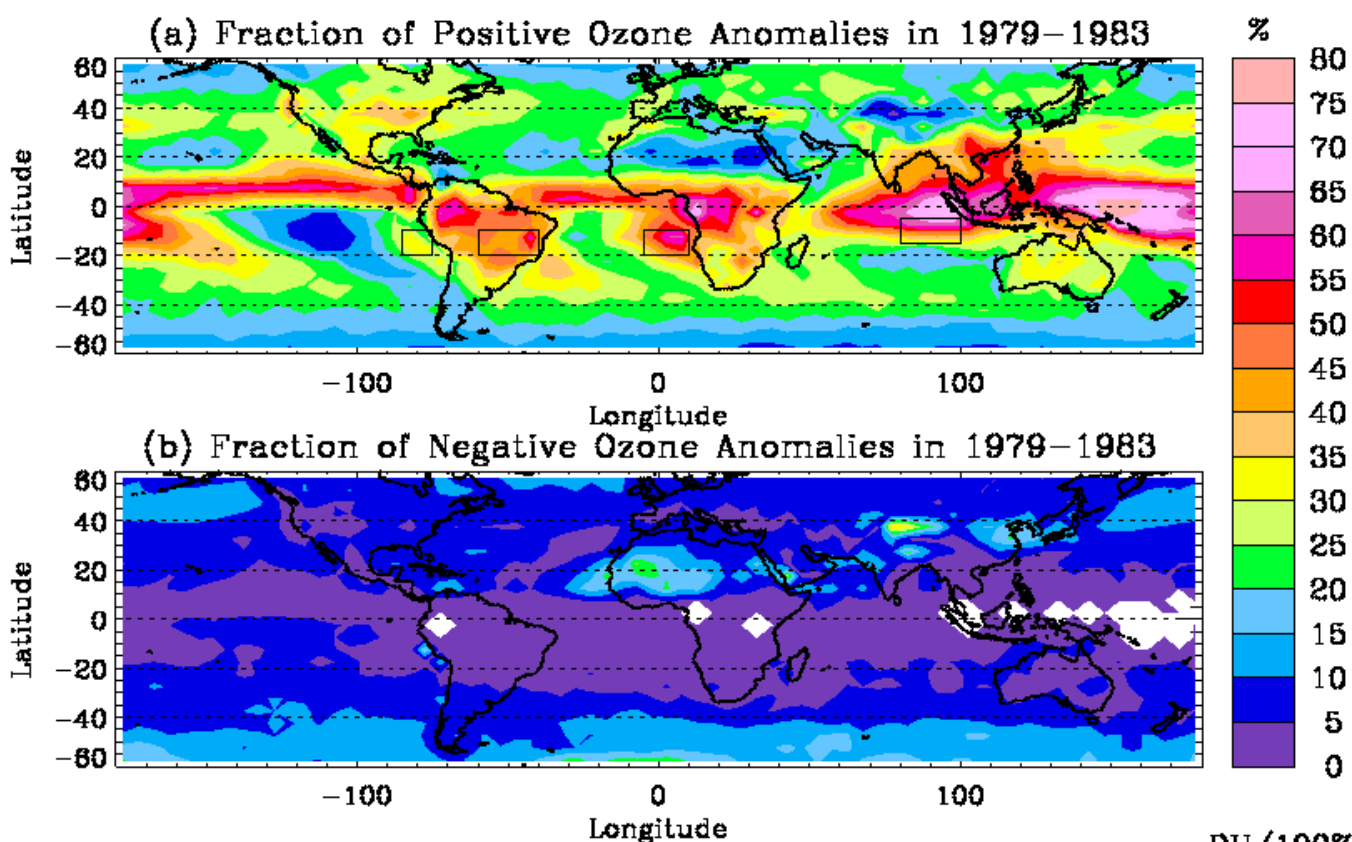

\section{DU/ $100 \%$}
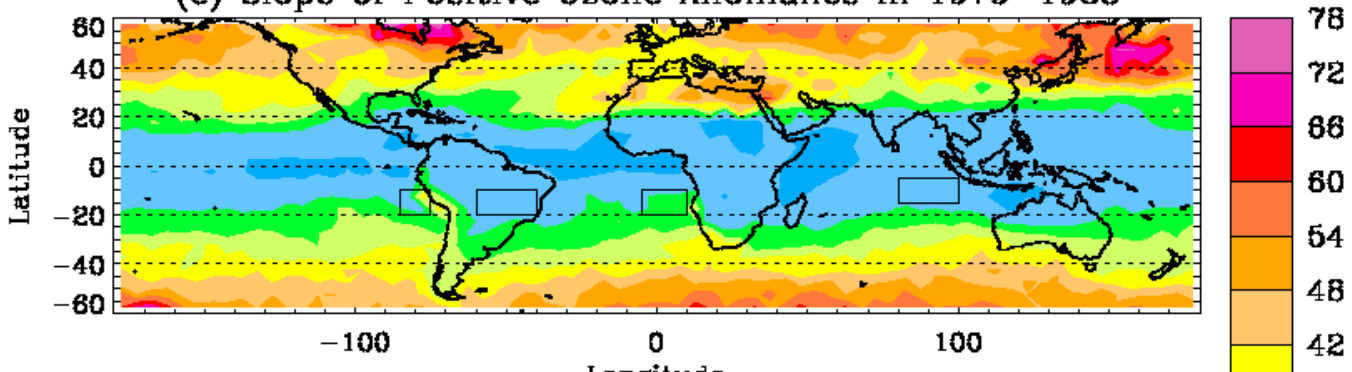

66

60

54

48

42

Longitude

(d) Minus Slope of Negative Ozone Anomalies in 1979-1983

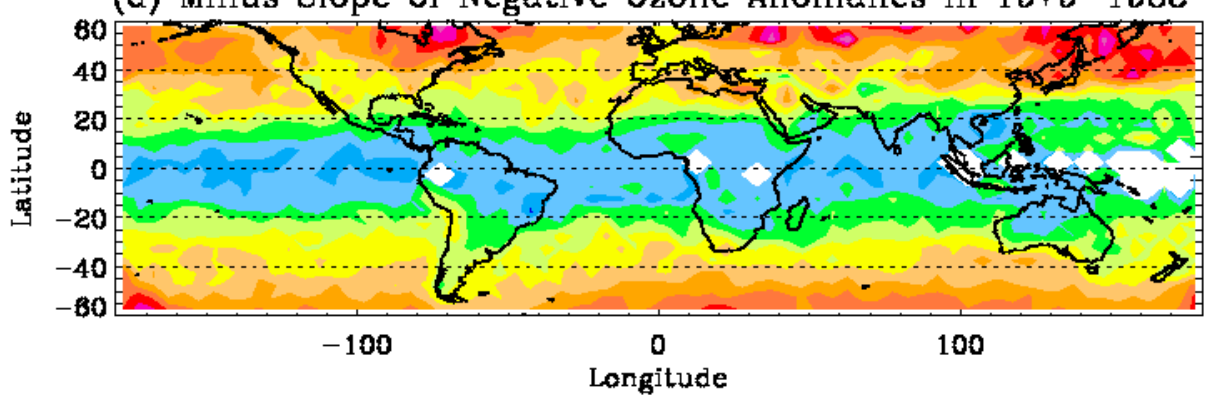

Fig. 8. Ozone anomalies in 1978-1983 period after the $\Delta \mathrm{P}$ correction. (a) Average spatial fraction distribution of positive ozone anomalies. (b) Same as (a) except for negative ozone anomalies. (c) and (d) Same as (a) and (b) except for the linear regression ozone/reflectivity slopes of ozone anomalies.

to El Niño events increases not only cloud occurrence but also cloud height over the eastern Pacific Ocean (Wang et al., 1996; Chandra et al., 1998; Bell et al., 1999). However, the ISCCP cloud climatology used in the TOMS V7 algorithm is from July 1983 to December 1990. When the ISCCP cloud climatology is not available during the other years, cloud climatology from mostly non-El Niño years is used. The assumed CTPs, mostly from $600 \mathrm{hPa}$ to $900 \mathrm{hPa}$ over the tropi- cal eastern Pacific Ocean in all months, are much higher than the actual CTPs during the 1982-1983 and 1997-1998 El Niño events, as shown in Fig. 9c, leading to the large increase in the fraction of NOAs. The much smaller increase in the fraction of NOAs for the 1986-1987 and 1991-1992 El Niño events relative to non-El Niño periods is because of the weaker El Niño activities during these periods. The used cloud climatology from 1986 and 1987 for the 1986-1987 El 
(a) Dec. 1981-Feb. 1982

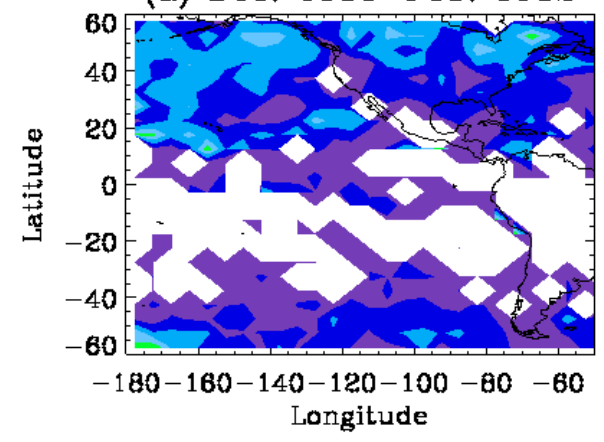

(b) Dec. $1982-F e b .1983$

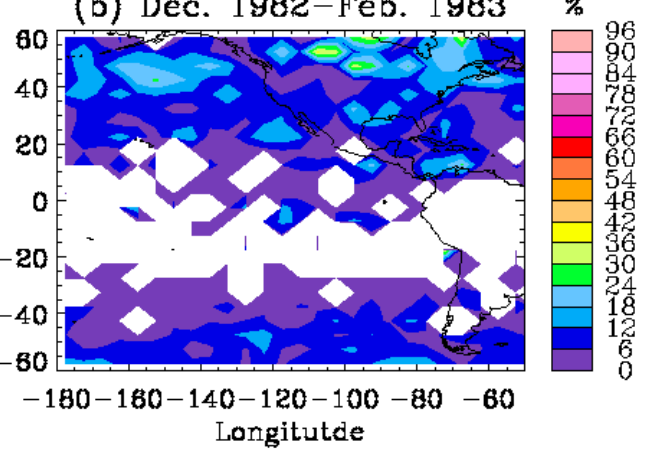

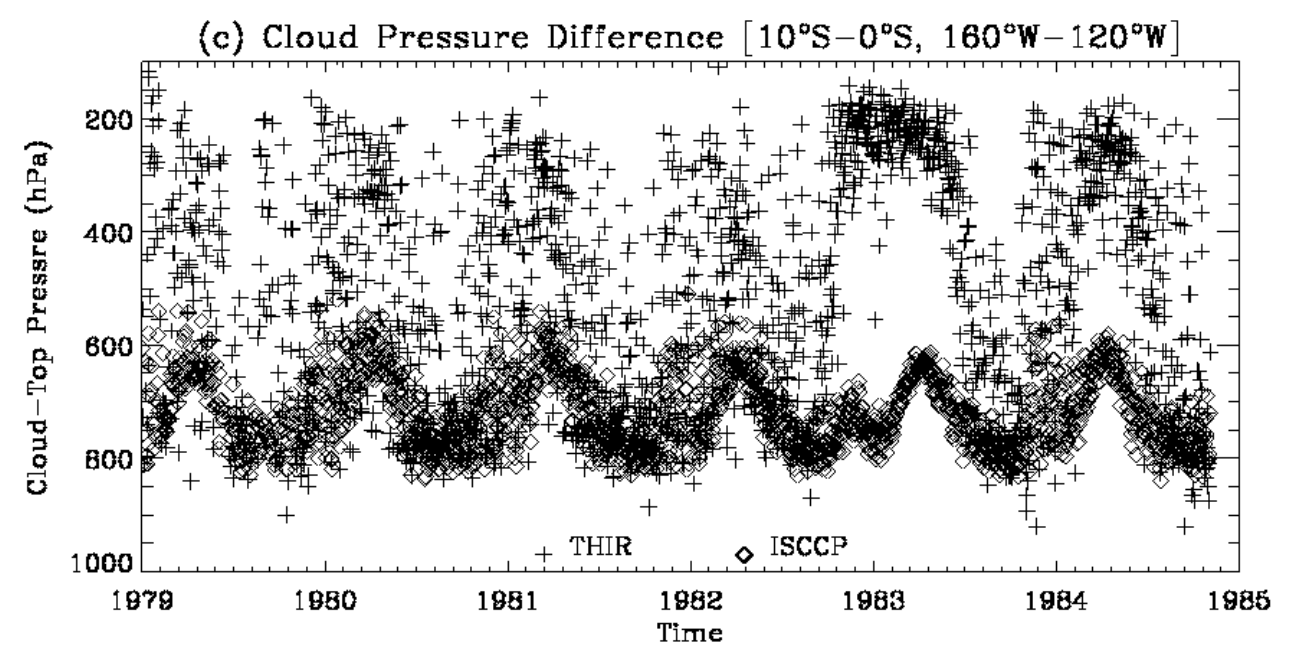

Fig. 9. (a) and (b) same as Fig. 6a and b except after the $\triangle \mathrm{P}$ correction. (c) comparison of daily ISCCP cloud-top pressures (diamond) used in the TOMS V7 ozone retrieval and collocated THIR cloud-top pressures (plus) during 1979-1984 averaged over the eastern Pacific Ocean $\left(10^{\circ} \mathrm{S}-0^{\circ} \mathrm{S}, 160^{\circ} \mathrm{W}-120^{\circ} \mathrm{W}\right)$ for scenes with reflectivity greater than $40 \%$.

Niño event also reduces the increase in NOAs.

Because the $\Delta \mathrm{P}$ correction is based on the TOMS standard ozone profiles, it would overestimate or underestimate the cloudy total ozone if the actual lower tropospheric ozone is different from the standard lower tropospheric ozone (Klenk et al., 1982; Hudson et al., 1995). The actual tropospheric ozone is usually smaller (larger) than the TOMS climatological tropospheric ozone over the Pacific Ocean (Atlantic Ocean) (Fishman et al., 1990; Hudson et al., 1998; Ziemke et al., 2000; Thompson et al., 2003); therefore, the $\Delta \mathrm{P}$ correction overestimates (underestimates) the fraction and slope of OAs over the western Pacific Ocean (Atlantic Ocean). Considering the incorrect climatological tropospheric ozone added below clouds to complete the total ozone column, the slope over the Atlantic Ocean and Africa will be higher than the slope over the Pacific Ocean. However, the extensive distribution of POAs across tropical regions indicates that considering the incorrect tropospheric ozone climatology would not have much effect on the overall OA distribution.

Figures $10 \mathrm{a}$ and $\mathrm{b}$ show the seasonal and latitudinal vari- ation of the zonal-mean fractions of POAs and NOAs, respectively, after the $\Delta \mathrm{P}$ correction during 1979-1983. The fraction of POAs at mid-latitudes peaks in the late spring and summer (25-30\%) and is lowest in the winter (10-20\%). The maximum fraction of POAs in the tropics follows the motion of the intertropical convergence zone, while the minimum occurrence in subtropical areas is located immediately north (south) of the tropical peak in the Northern (Southern) Hemisphere. The above zonal feature and the seasonal variation of POAs are consistent with cloud occurrence in these regions (Stowe et al., 1989; Wang et al., 1996). There is much less variation for NOAs except in the Southern Hemisphere $50^{\circ} \mathrm{S}-60^{\circ} \mathrm{S}$. NOAs in this region peak in the late austral winter and early austral spring when the area is frequently covered with sea ice. Figures 10c and d are similar to Figs. 10a and $\mathrm{b}$ but Figs. 10c and $\mathrm{d}$ are for ozone/reflectivity slopes. POAs and NOAs show similar variations. At mid-latitudes, the slope is highest from winter to early spring in both hemispheres with a magnitude of 60-80 DU/100\%, and is lowest in summer and fall with a magnitude of $30-40$ DU/100\%. 

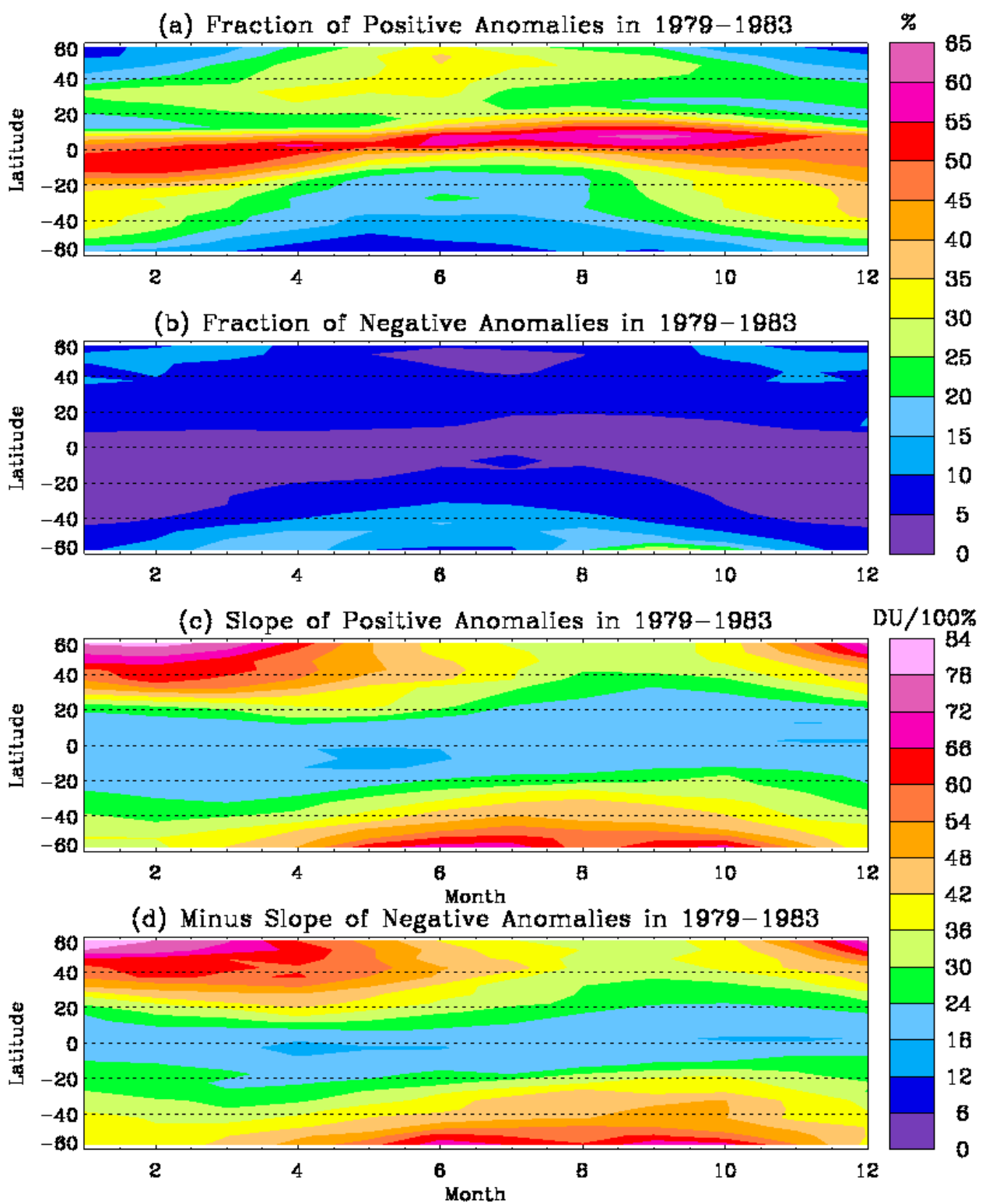

Fig. 10. Seasonal and latitudinal variation of ozone anomalies during 1979-1983 after the $\Delta \mathrm{P}$ correction. (a) and (b) are zonal average fractions of occurrence for positive and negative ozone anomalies, respectively. (c) and (d) are similar to (a) and (b) except for zonal average ozone/reflectivity slopes.

The peak of the OA slope migrates toward the equator later in the spring. In tropical areas, the slope shows very little seasonal variation, with a magnitude of $18-24$ DU/100\%.

\subsection{Ozone retrieval errors associated with clouds}

More than $90 \%$ of the OAs after the $\triangle \mathrm{P}$ correction in tropical convective cloudy areas are POAs. Newchurch et al. (2001) discussed the causes of persistent cloudy TOC excess relative to clear areas in these regions. The dynamics effects due to cumulonimbus penetration and enhanced chemical production above high clouds are shown to be negligible in ac- counting for the large cloudy ozone excess. The TOC fluctuation in terms of root mean square day-to-day difference is about 2-3 DU and the primary source appears to be Kelvin waves (Allen and Reck, 1997). This smaller variation in TOC could not lead to extensive POAs in tropical convective cloudy areas. Furthermore, Kelvin waves originate primarily from the lower-to-middle stratosphere region (Ziemke and Standard, 1994) and are not correlated with cloud fields. Then the cloudy ozone excess over those high-altitude and high-reflectivity clouds must be caused primarily by ozone retrieval errors. 
About $\sim 5$ DU ozone excess is probably caused by nonlinearity calibration errors in the N7 TOMS data (Newchurch et al., 2001). Newchurch et al. (2001) speculate that the remaining cloudy ozone excess is caused by ozone absorption inside the clouds. Although not all the backscattered photons at TOA penetrate the clouds, but the photon path lengths for those penetrating photons are enhanced because of the incloud multiple scattering, and so is ozone absorption inside the clouds (Kurosu et al., 1997; Mayer et al., 1998). Radiative transfer calculations corroborate this speculation. At nadir view and for a $2-12 \mathrm{~km}$ water cloud with 21 DU ozone homogeneously distributed in the cloud, the TOC is overestimated by $18 \mathrm{DU}$ and $11 \mathrm{DU}$ for cloud optical depth 40 and 500, respectively (Liu, 2002). The ozone absorption enhancement in the clouds is largely dependent on viewing geometry and on ozone distribution and amount in the clouds. It is estimated that the enhanced ozone is about 5-13 DU over the tropical Atlantic Ocean and Africa and 1-7 DU over the Pacific Ocean (Liu, 2002).

Note that positive errors because of intra-cloud ozone absorption and nonlinearity calibration offset negative errors induced by incorrect cloud heights. Therefore, the fraction of OA occurrence is reduced in the TOMS V7 level-2 data (i.e. before the $\Delta \mathrm{P}$ correction) as shown from the comparison of the OA distribution before and after the $\Delta \mathrm{P}$ correction.

\subsection{Planetary-scale and synoptic-scale activities}

Large negative ozone retrieval errors induced by cloud height errors and positive errors due to ozone absorption enhancement in the clouds also occur at mid-latitudes. However, the large average ozone/reflectivity slope at mid-latitudes suggests that mid-latitude OAs are controlled mainly by other factors. Allen and Reck (1997) analyzed the daily variations of TOC in 1979-1992 TOMS V7 data. The seasonal and latitudinal variation of root mean square day-to-day differences (Fig. 1d in Allen and Reck, 1997) shows a pattern very similar to that in Figs. 10c and d. Root mean square day-to-day differences maximize near $30 \mathrm{DU}$ at mid-latitudes from late fall to early spring, and minimize near $16 \mathrm{DU}$ in the summer. Stanford et al. (1996) analyzed the interannual variability of TOMS version-6 TOC and also found similar seasonal variation. The contributions of these fluctuations at mid-latitudes result primarily from synoptic and planetary wave activities (Allen and Reck, 1997; Stanford et al., 1996). The consistency of seasonal variation between the ozone/reflectivity slope and the total ozone fluctuations suggests that both POAs and NOAs at mid-latitudes are caused mainly by synoptic and planetary wave disturbances.

Synoptic-scale systems have long been recognized as sources of TOC variability (Dobson and Harrison, 1926; Dobson et al., 1928). Recent studies have examined the influence of middle latitude disturbance on total ozone distribution using satellite data (Vaughan and Price, 1991; Salby and Callaghan, 1993; Hudson and Frolov, 2000; Olsen and Stan- ford, 2001). The dynamic disturbance associated with synoptic weather systems and planetary-wave activities can change lower stratospheric ozone with a magnitude up to $30 \%$ of the TOC in the mid- and high-latitudes (WMO, 1998; Olsen and Stanford, 2001). Of planetary-scale and synoptic-scale disturbances, the latter contributes more to the daily TOC fluctuation except during the austral spring, where vortex contortions and break-ups lead to large planetary-scale disturbances (Stanford et al., 1996; Allen and Reck, 1997). Strong dynamic disturbances associated with synoptic phenomena such as jet streams and fronts are also associated with strong clouds. More clouds in the mid-latitudes are formed in the east of a trough (above a surface low-pressure system), where the vertical upward motion brings humid surface air upward. Because high ozone and cloud patterns are usually associated with surface low-pressure systems in the mid-latitudes, they combine to form POAs. The much higher fraction of POAs than NOAs at mid-latitudes supports the fact that high TOC is usually associated with cyclones and low TOC is usually associated with anticyclones over pollution-free regions. However, there are exceptions to this ozone-meteorological relationship, as we can see from the smaller fraction of NOAs.

One particular region with more NOAs than POAs occurs near $60^{\circ} \mathrm{S}$. Both fraction and ozone/reflectivity slope of NOAs in this region peak during September and early October, when the area is frequently covered with sea ice. The polar vortex break-up leads to large planetary-scale disturbance and large TOC fluctuations outside the polar vortex (Stanford et al., 1996; Allen and Reck, 1997), while catalytic ozone depletion largely decreases the ozone inside the polar vortex (Seinfeld and Pandis, 1997). The reflectivity of the snow/ice surface inside the polar vortex is very high, and the reflectivity under clear conditions outside the polar vortex is lower because of higher temperature. Therefore, higher reflectivity ice and lower ozone inside the polar vortex, and lower reflectivity and higher ozone outside the polar vortex probably cause the formation of these NOAs.

4.4 Marine stratocumulus clouds and enhanced tropospheric ozone

The $\triangle \mathrm{P}$ correction reduces the fraction of POAs off the WCSAF and WCSAM by $5-10 \%$; however, the remaining high fraction of $30-60 \%$ POAs indicates that these POAs are caused mainly by factors other than incorrect cloud-top heights. Figure 11 shows the seasonal variation of fraction (a) and ozone/reflectivity slope (b) of POAs for these two selected regions (boxes in Figs. 8a and c), along with the monthly variation of fraction and slope over the Indian Ocean and South America for comparison. The fractions of POAs for these four regions are slightly different and basically agree with the occurrence of high-reflectivity convective clouds or marine stratocumulus clouds (Stowe et al., 1989; Thompson et al., 1993). However, the two marine stratocumulus regions and the two convective cloudy areas show 
(a) Monthly Variation of Fraction (1979-1983)

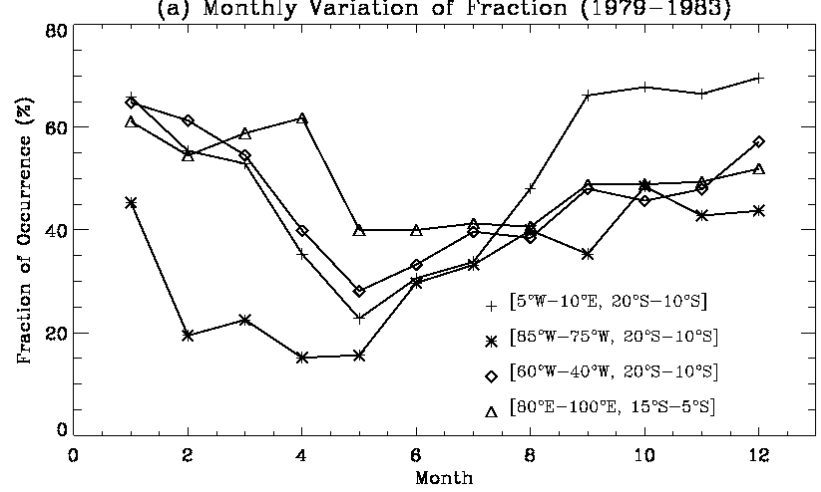

(b) Monthly Variation of Slope (1979-1983)

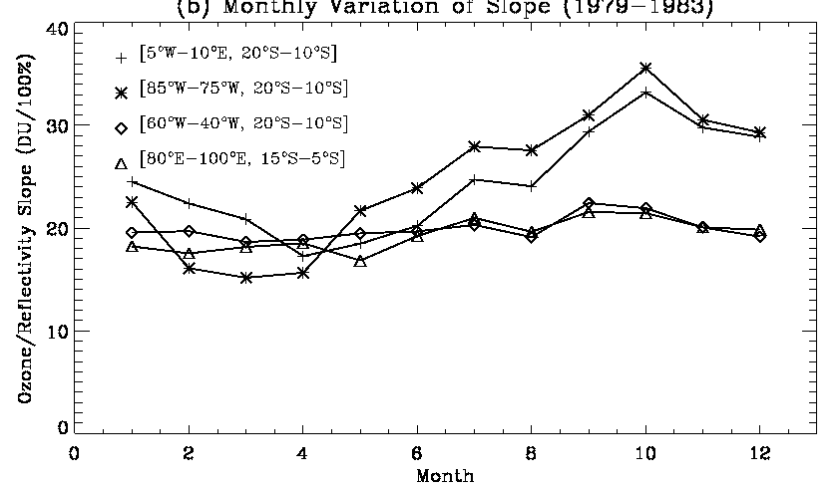

Fig. 11. (a) Seasonal variations of fraction of positive ozone anomalies after the $\Delta \mathrm{P}$ correction during 1979-1983 off the west coast of South Africa $\left(20^{\circ} \mathrm{S}-10^{\circ} \mathrm{S}, 5^{\circ} \mathrm{W}-10^{\circ} \mathrm{E}\right)$, off the west coast of South America $\left(20^{\circ} \mathrm{S}-10^{\circ} \mathrm{S}, 85^{\circ} \mathrm{W}-75^{\circ} \mathrm{W}\right)$, over South America $\left(20^{\circ} \mathrm{S}-10^{\circ} \mathrm{S}, 60^{\circ} \mathrm{W}-40^{\circ} \mathrm{W}\right)$, and over the Indian Ocean $\left(15^{\circ} \mathrm{S}-\right.$ $5^{\circ} \mathrm{S}, 80^{\circ} \mathrm{E}-100^{\circ} \mathrm{E}$ ). (b) Same as (a) except for ozone/reflectivity slope.

obviously different slope variations. The two convective cloudy areas show very little slope variation, 20 DU/100\% throughout the year. The ozone/reflectivity slope in marine stratocumulus regions, however, maximizes from September to December (30-35 DU/100\%) and minimizes from February to May off the WCSAF and WCSAM (15-18 DU/100\%). The different seasonal variations in slope indicate that POAs off the WCSAF and WCSAM are caused by different mechanisms from POAs in tropical convective cloudy areas. The observed tropospheric ozone in these regions also shows similar seasonal patterns, highest from August to November (i.e. the biomass burning season) and lowest from February to April (Fishman et al., 1990; Kirchhoff et al., 1996; Jiang and Yung, 1996; Thompson et al., 1996; Kim and Newchurch, 1996, 1998). For example, the correlation coefficient between the slope variation at WCSAF and the 1998-2000 SHADOZ monthly mean tropospheric ozone at Ascension (Thompson et al., 2003) is 0.95. Because of the similar seasonal patterns between the slope of POAs and tropospheric ozone, we conjecture that these POAs are related to both tro- (a) Monthly Mean Trop. Profile at Ascension (1998-2000)

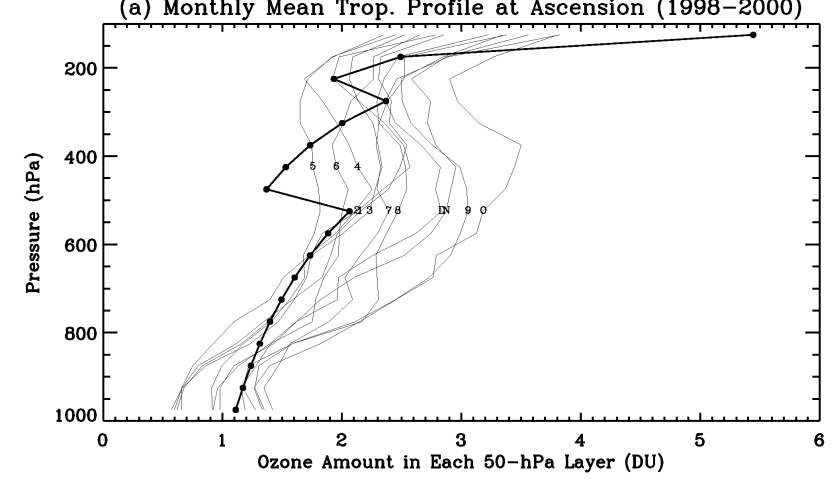

(b) ISCCP D1 CTP vs. COD (October 1983)

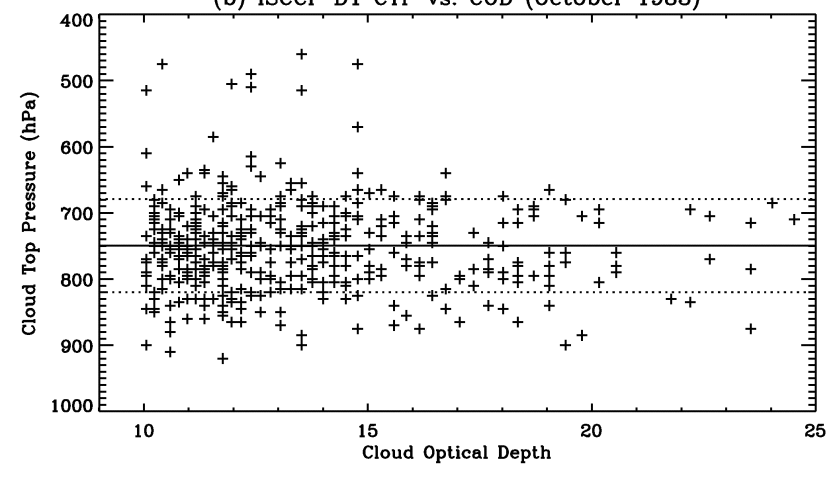

Fig. 12. (a) Monthly mean tropospheric ozone profiles measured at Ascension (1998-2000) along with the tropospheric portion of TOMS standard ozone profile L275 (curve with symbols). Each curve without symbols is identified by a character (1-9 for JanuarySeptember, O, N, and D for October, November, and December). (b) ISCCP D1 cloud-top pressure vs. cloud optical depth in October 1983 off the west coast of South America $\left(20^{\circ} \mathrm{S}-10^{\circ} \mathrm{S}, 5^{\circ} \mathrm{W}-\right.$ $\left.10^{\circ} \mathrm{E}\right)$. Solid line is the average cloud-top pressure, and the two dashed lines are 1 standard deviation from the average value.

pospheric ozone distribution and the existence of marine stratocumulus clouds.

SHADOZ project established a network of 10 southern hemisphere tropical and subtropical stations to perform regularly measurements of ozone profiles (Thompson et al., 2003). The station at Ascension is very close to WCSAF. To understand the formation of POAs in these regions of marine stratocumulus, we simulate the ozone/reflectivity slope at WCSAF using 1998-2000 SHADOZ measurements at Ascension. Figure 12a shows the monthly mean tropospheric ozone profiles along with the low-latitude TOMS standard profile with a TOC of 275 DU (33.8 DU tropospheric ozone), which is called "L275." The tropospheric ozone column integrated from $1000 \mathrm{hPa}$ to $100 \mathrm{hPa}$ profiles in Fig. 12a at Ascension ranges from 29.0 DU in April to 48.7 DU in October. We use the Ascension tropospheric ozone profiles (up to $100 \mathrm{hPa}$ ) along with the stratospheric of L275 for both clear and cloudy conditions. We treat clouds as scattering clouds 


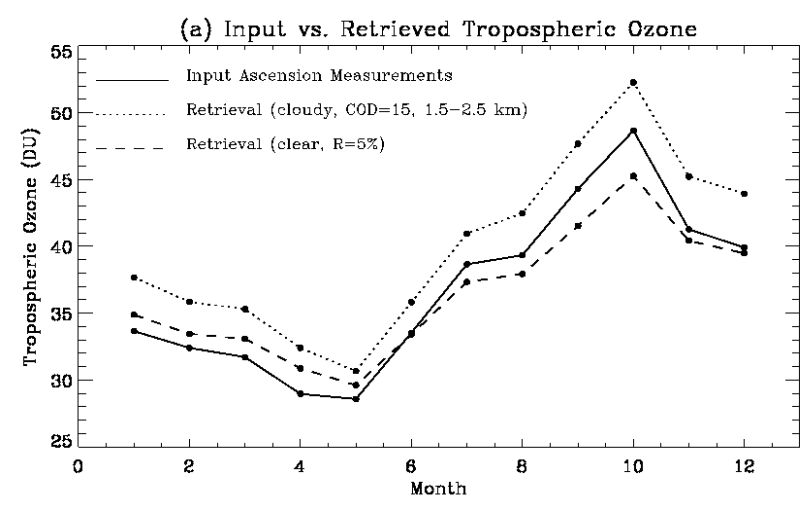

(b) Monthly Variation of Slope at $\left[5^{\circ} \mathrm{W}-10^{\circ} \mathrm{E}, 20^{\circ} \mathrm{S}-10^{\circ} \mathrm{S}\right]$

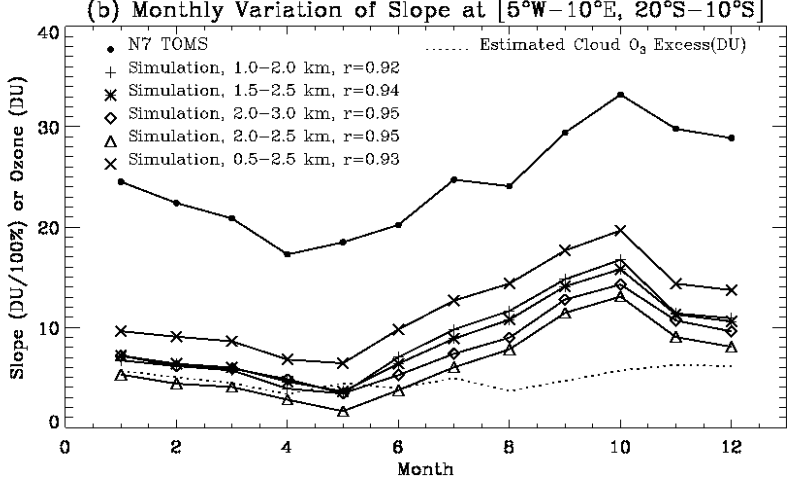

Fig. 13. (a) Monthly variation of tropospheric ozone measured at Ascension during 1998-2000 (solid line); the retrieved ozone for a cloudy-sky with a water cloud of cloud optical depth 15 at $1.5-2.5 \mathrm{~km}$ (dotted line); and the retrieved ozone for a clear-sky with ground reflectivity of $5 \%$. (b) Monthly variation of the observed ozone/reflectivity slope (circles) off the west coast of South Africa, estimated cloudy ozone excess (dotted line), and simulated ozone/reflectivity slopes under various cloudy conditions.

instead of Lambertian surfaces. For all the POAs at WCSAF, the average maximum reflectivity from TOMS data is about $55 \%$, corresponding to a water cloud of optical depth $\sim 15$. Figure $12 \mathrm{~b}$ shows the ISCCP D1 CTP at WCSAF $\left(5^{\circ} \mathrm{W}-\right.$ $10^{\circ} \mathrm{E}, 20^{\circ} \mathrm{S}-10^{\circ} \mathrm{S}$ ) in October 1983 for clouds with a COD $>10$ (Rossow et al., 1996). The average CTP is $749.5 \mathrm{hPa}$ with 1 standard variation of $70 \mathrm{hPa}$. We simulate the cloud as a stratocumulus cloud of COD 15 with a geometrical depth of $1 \mathrm{~km}$ at $1.5-2.5 \mathrm{~km}$ (i.e. $852 \mathrm{hPa}-756 \mathrm{hPa}$ ). For a clearsky condition, we assume a Lambertian surface of reflectivity $5 \%$ at $1013.15 \mathrm{hPa}$ (Herman and Celarier, 1997; Herman et al., 2001). We use polarized Gauss-Seidel radiative transfer model (Herman et al., 1995) to simulate radiances for the assumed clouds, and use the TOMS V7 algorithm to retrieve the TOC for both clear and cloudy conditions. In the simulation and retrieval, we assume the average TOMS observation viewing geometry for this region, $\mathrm{SZA} \approx 20^{\circ}$ and $\mathrm{VZA}$ $\approx 20^{\circ}$.

Figure 13a shows the monthly variation of retrieved tropospheric ozone for both clear and cloudy conditions. Under clear conditions, the retrieved tropospheric ozone is higher than the input tropospheric ozone by $0.3-1.2 \mathrm{DU}$ from January to May and smaller by $0.8-4.0 \mathrm{DU}$ from June to December because the imperfect retrieval efficiency is smaller than 1 at TOMS wavelengths (Hudson et al., 1995). Under cloudy conditions, the retrieved tropospheric ozone is always overestimated because of a combination of various ozone retrieval errors including radiation interpolation error $(\sim 0.7 \mathrm{DU})$, ozone absorption enhancement in the clouds (from 1.4 DU in April to 2.7 DU in October), error in added ozone below clouds (from $-1.0 \mathrm{DU}$ in October to $1.4 \mathrm{DU}$ in April), and error due to imperfect retrieval efficiency that is slightly greater than 1 (from $-0.8 \mathrm{DU}$ in May to $1.6 \mathrm{DU}$ in October).

From the retrieved ozone difference between clear and cloudy conditions, we can derive the simulated ozone/reflectivity slopes. Figure $13 \mathrm{~b}$ shows the monthly variation of the simulated ozone/reflectivity slopes. There is a high correlation of 0.94 between the simulated slope and the observed slope of POAs. However, the simulated slope is smaller than the observed slope by $12.7-18.4$ DU/100\%, and the simulated slope difference between the maximum and minimum is $12.2 \mathrm{DU} / 100 \%, 0.76$ of the corresponding observed value. Figure $13 \mathrm{~b}$ also shows the simulated slopes for the same cloud except at $1-2 \mathrm{~km}, 2-3 \mathrm{~km}, 2-2.5 \mathrm{~km}$, and $0.5-$ $2.5 \mathrm{~km}$. The maximum and minimum slope difference varies within $\pm 4 \mathrm{DU}$ for these four cloudy conditions. The increase of cloud geometrical depth to $2 \mathrm{~km}$ increases the slopes by 2.2-3.9 DU/100\% because the enhanced ozone changes with the amount of ozone in the clouds. The further increase of the cloud geometrical depth can match the observed value but the cloud thickness for stratocumulus clouds is typically about $500-1000 \mathrm{~m}$. With all the known ozone retrieval errors considered, the simulated slopes are still far below the observed values. About 6 DU/100\% in the difference between observed and simulated slopes can be ascribed to nonlinearity calibration error if the N7/EP bias results from N7 TOMS data only. We suggest that the remaining simulated and observed difference results mainly from there being more ozone over cloudy areas than over clear areas due to chemical production. Approximately 3.3-6.2 DU cloudy ozone excess (dotted line in Fig. 13b) is required to explain the observed slopes for the cloud at $1.5-2.5 \mathrm{~km}$. High reflectivity marine stratocumulus clouds increase the actinic flux and therefore increase the photolysis rates to produce ozone above lowaltitude clouds (Madronich, 1987; Pfister et al., 2000). Pfister et al. (2000) show that the $j_{\mathrm{O}_{3}}$ above clouds is about 50\% higher than the corresponding clear-sky values. Because there is a high frequency of stratocumulus clouds (Thompson et al., 1993; Stowe et al., 1989) and rich ozone precursors during the biomass season at WCSAF (Lee et al., 1998), it is possible to photochemically produce $3-6 \mathrm{DU}$ more ozone relative to clear-sky conditions. Measurements and photochemical models are needed to further examine this speculation. 


\subsection{Solar zenith angle and satellite zenith angle}

The effects of satellite view zenith angle on TOMS TOC are apparent during the Mount Pinatubo eruption, with an order of $2 \%$ (Bhartia et al., 1993; Torres and Bhartia, 1995). Small scan-angle dependence, on the order of $1 \%$, remains in the TOMS TOC even in the absence of aerosols (McPeters et al., 1996). In a $5^{\circ}$-longitude by $5^{\circ}$-latitude area, the solar zenith angle does not change much for different measurements, and the view zenith angle is usually within $20^{\circ}$. We examined both correlation coefficients and slopes between ozone and reflectivity to be a function of average solar zenith angle and view zenith angle, but we did not find any relationship between OAs and viewing geometry.

\section{Effects of ozone anomalies on TOMS applications}

Analysis of OAs indicates that some OAs are caused by ozone retrieval errors. Including the cloudy total ozone that contains ozone retrieval errors will affect the corresponding results in particular applications such as calculation of monthly mean ozone climatology, analysis of the ozone seasonal variation, evaluation of ozone trends, and tropospheric ozone derivation.

However, analysis of the effects of clouds on these applications is very complicated, because the overall effect of different types of errors depends on factors such as cloud altitude, cloud-height errors, cloud fraction, and ozone amount and distribution in the clouds. In the archived TOMS V7 level-2 data, the mainly negative cloud-height errors and other positive errors usually partly cancel, leading to an overall smaller error in cloudy areas. In applications related to global mean or zonal mean, the overall error is expected to be small. In some regions, such as oceanic regions off the west coast of South Africa and off the west coast of South America, errors in cloudy-sky measurements tend to cancel errors in clearsky measurements, leading to small errors in the gridded level-3 data. For studies of a particular region during a special period, however, special care should be taken regarding the effects of clouds in those regions with high frequencies of POAs and NOAs. For example, over the eastern Pacific Ocean during El Niño periods, there would be persistent negative errors of about $-10 \mathrm{DU}$ in cloudy areas caused from using the incorrect cloud climatology mostly from non-El Niño periods.

OAs have important implication for applications using the clear/cloudy ozone differences, such as the ConvectiveCloud Differential (CCD) (Ziemke et al., 1998) and the Clear-Cloudy Pairs (CCP) (Newchurch et al., 2002) methods. Even without accounting for ozone retrieval error above clouds, one can retrieve reasonable tropospheric ozone with special sampling, such as using the monthly minimum ozone above clouds in the CCD method and the mean of the six lowest values of ozone above clouds within five days in the CCP method. However, at mid-latitudes, the large ozone/reflectivity slope due to planetary and synoptic wave disturbances makes it risky to apply the CCD or CCP methods unless we can develop a method to account for these wave effects. The N7/EP TOMS bias leads to the offset in the derived tropospheric ozone as well.

Knowledge of these different types of errors is important for studies using TOMS measurements because these errors might significantly affect particular applications. In addition, we have experienced some self-correcting effect in the TOMS data; i.e. errors of opposite sign partly cancel each other and lead to small errors in the archived TOMS data. Therefore, it is possible that correcting only one of these errors could lead to larger overall errors. Future instruments such as the OMI can avoid cloud-height-related errors by accurately determining cloud heights from visible and infrared channels. Then large errors in the retrieved ozone will come mainly from the ozone absorption enhancement in the clouds.

\section{Summary}

To characterize the frequency of occurrence of anomalous ozone distribution, we define that a $5^{\circ}$ by $5^{\circ}$ region contains a Positive Ozone Anomaly (POA) or Negative Ozone Anomaly (NOA) if the correlation coefficient between ozone and reflectivity is $\geq 0.5$ or $\leq-0.5$, respectively. We investigate the Ozone Anomaly (OA) distribution in Nimbus-7 (N7) TOMS data during 1979-1992 and in Earth-Probe (EP) TOMS data during 1997-1999 and analyze the causes of OA formation.

The average fractions of OAs among all cloud fields in N7 and EP TOMS are $31.8 \pm 7.7 \%$ and $35.8 \pm 9.7 \%$, respectively. OAs are not evenly distributed on the globe, and some regions are dominated with a high number of POAs or NOAs. But the spatial distributions of OAs are similar from year to year except for the obvious El Niño/non-El Niño and N7/EP contrasts. El Niño events do not cause much change to the annual average fraction, but they do produce significant regional effects. The 1982-1983 and 1997-1998 El Niño events increase the fraction of NOAs over the tropical eastern Pacific Ocean by 40\% during December-February. During the EP TOMS period, there are more NOAs but fewer POAs relative to the N7 TOMS period, especially in tropical areas. The linear regression slope between total ozone and reflectivity for OAs is mainly a function of latitude, increasing from $12-30$ DU/100\% in tropical areas to $36-84$ DU/100\% in midlatitudes.

Some OAs are caused by ozone retrieval errors, and others result primarily from geophysical phenomena. Large errors in Cloud-Top Pressure (CTP) are observed in the TOMS V7 algorithm in comparison with spatially and temporally colocated Temperature Humidity Infrared Radiometer (THIR) cloud data on board the N7 satellite. The assumed cloud- 
top pressures are usually overestimated by $\sim 200 \mathrm{hPa}$ for high-altitude clouds (THIR CTP $\leq 200 \mathrm{hPa}$ ) and underestimated by about $\sim 150 \mathrm{hPa}$ for low-altitude clouds (THIR $\mathrm{CTP} \geq 750 \mathrm{hPa}$ ). Correcting the cloud-height errors eliminates most tropical NOAs even during El-Niño periods, but dramatically increases the fraction of POAs by $20-50 \%$ in tropical convective cloudy areas. Tropical NOAs are mainly caused by negative ozone retrieval errors induced by incorrect cloud heights. Most tropical POAs result from positive errors due to ozone absorption enhancement in the clouds and probably nonlinearity calibration in N7 TOMS data. The fact that correcting cloud height errors dramatically increases POAs indicates that negative and positive errors offset each other, leading to fewer OAs in TOMS data. The slope of POAs and NOAs at mid-latitudes peaks from late fall to early spring (60-80 DU/100\%) and is lowest in the summer (30-40 DU/100\%). The seasonal variation of slope is consistent with that of total ozone fluctuation, indicating that mid-latitude OAs are mainly caused by planetary-scale and synoptic-wave disturbances. The slope of POAs in marine stratocumulus regions off the west coast of South Africa and off the west coast of South America shows a maximum from August to November (i.e. the biomass burning season) and a minimum from February to May, highly correlated with the tropospheric ozone variation in these regions. About half of the slope can be explained by ozone retrieval errors under both clear and cloudy conditions. We speculate that there is more ozone over cloudy areas because of the enhanced photolysis rates over high frequency of low-altitude marine stratocumulus clouds and rich ozone precursors above these clouds. About 3-6 DU cloudy ozone excess is required to explain the remaining unexplained slope. However, further studies using measurements and photochemical models are needed to examine this speculation.

Acknowledgements. We are grateful to the NASA Earth Science Enterprise for supporting this research through the NASA/ACMAP and fostering this international collaboration with the Korean Ministry of Science and Technology. We thank P. K. Bhartia, C. G. Wellemeyer, R. D. Hudson, J. Ziemke, R. D. McPeters, and S. Chandra for enlightening discussions concerning the mechanisms for formation of ozone anomalies and for hosting X. Liu during his summer study at GSFC. We wish to thank the Ozone Processing Team at GSFC for providing the TOMS data and processing capability.

\section{References}

Allen, D. R. and Reck, R. A.: Daily variations in TOMS total ozone data, J. Geophys. Res., 102, 13 603-13 608, 1997.

Bell, G. D., Halpert, M. S., Ropelewski, C. F., Kousky, V. E., Douglas, A. V., Schnell, R. C., and Gelman, M. E.: Climate assessment for 1998, Bull. Amer. Meteor. Soc., 80, S1-S48, 1999.

Bhartia, P. K., Herman, J. R., and McPeters, R. D.: Effect of Mount Pinatubo aerosols on total ozone measurements from Backscatter
Ultraviolet (BUV) Experiments, J. Geophys. Res., 98, $18547-$ $18554,1993$.

Chandra, S., Ziemke, J. R., Min, W., and Read, W. G.: Effects of 1997-1998 El Niño on tropospheric ozone and water vapor, Geophys. Res. Lett., 25, 3867-3870, 1998.

Cuevas, E., Gil, M., Rodriguez, J., Navarro, M., and Honka, K. P.: Sea-land total ozone difference from TOMS: GHOST effect, J. Geophys. Res., 106, 27 745-27 755, 2001.

Dobson, G. M. B. and Harrison, D. N.: Measurements of the amount of ozone in the Earth's atmosphere and its relation to other geophysical conditions, Proc. R. Soc. London A, 110, 660693, 1926.

Dobson, G. M. B., Harrison, D. N.: and Lawrence, J., Measurements of the amount of ozone in the Earth's atmosphere and its relation to other geophysical conditions, Proc. R. Soc. London A, 122, 456-486, 1928.

Fishman, J., Watson, C. E., Larsen, J. C., and Logan, J. A.: Distribution of tropospheric ozone determined from satellite data, J. Geophys. Res., 95, 3599-3617, 1990.

Herman, B. M., Caudill, T. R., Flittner, D. E., Thome, K. J., and Ben-David, A.: Comparison of the Gauss-Seidel spherical polarized radiative transfer code with other radiative transfer codes, Appl. Opt., 34, 4563-4572, 1995.

Herman, J. R., Celarier, E. A., and Larko, D.: UV 380 nm reflectivity of the Earth's surface, clouds, and aerosols, J. Geophys. Res., 106, 5335-5351, 2001.

Herman, J. R. and Celarier, E. A.: Earth surface reflectivity climatology at 340-380 nm from TOMS data, J. Geophys. Res., 102, 28 003-28 011, 1997.

Hsu, N. C., McPeters, R. D., Seftor, C. J., and Thompson, A. M.: Effect of an improved cloud climatology on the total ozone mapping spectrometer total ozone retrieval, J. Geophys. Res., 102, 4247-4255, 1997.

Hudson, R. D. and Frolov, A. D.: Separation of total ozone by meteorological regimes, The Scientific Program of Quadrennial Ozone Symposium, Sapporro, 2000.

Hudson, R. D. and Thompson, A. M.: Tropical tropospheric ozone from Total Ozone Mapping Spectrometer by a modified residual method, J. Geophys. Res., 103, 22 129-22 145, 1998.

Hudson, R. D., Kim, J. H., and Thompson, A. M.: On the derivation of tropospheric column ozone from radiances measured by the total ozone mapping spectrometer, J. Geophys. Res., 100, 11 137-11 145, 1995.

Jiang, Y. and Yung, Y. L.: Concentrations of tropospheric ozone from 1979 to 1992 over tropical Pacific South America from TOMS data, Science, 272, 714-716, 1996.

Kim, J. H. and Newchurch, M. J.: Climatology and trends of tropospheric ozone over the eastern Pacific Ocean: The influences of biomass burning and tropospheric dynamics, Geophys. Res. Lett., 23, 3723-3726, 1996.

Kim, J. H. and Newchurch, M. J.: Biomass-burning influence on tropospheric ozone over New Guinea and South America, J. Geophys. Res., 103, 1455-1461, 1998.

Kirchhoff, V. W. J. H., Alves, J. R., da Silva, F. R.: and Fishman, J.: Observations of ozone concentrations in the Brazilian cerrado during the TRACE A field expedition, J. Geophys. Res., 101, 24 029-24 042, 1996.

Klenk, K. F., Bhartia, P. K., Fleig, A. J., Kaveeshwar, V. G., McPeters, R. D., and Smith, P. M.: Total ozone determination 
from the Backscattered Ultraviolet (BUV) experiment, J. Appl. Meteorol., 21, 1672-1684, 1982.

Kurosu, T., Rozanov, V. V., and Burrows, J. P.: Parameterization schemes for terrestrial water clouds in the radiative transfer model GOMETRAN, J. Geophys. Res., 102, 21 809-21 823, 1997.

Lee, M., Heikes, B. G., and Jacob, D. J.: Enhancements of hydroperoxides and formaldehyde in biomass burning impacted air and their effect on atmospheric oxidant cycles, J. Geophys. Res., 103, 13 201-13 212, 1998.

Liu, X., Ozone retrieval errors associated with clouds in Total Ozone Mapping Spectrometer (TOMS) data, Ph.D. Dissertation, University of Alabama in Huntsville, Huntsville, 2002.

Mayer, B., Kylling, A., Madronich, S., and Seckmeyer, G.: Enhanced absorption of UV radiation due to multiple scattering in clouds: Experimental evidence and theoretical explanation, J. Geophys. Res., 103, 31 241-31 254, 1998.

McPeters, R. D., Bhartia, P. K., Krueger, A. J., Herman, J. R., Schlesinger, B. M., Wellemeyer, C. G., Seftor, C. J., Jaross, G., Taylor, S. L., Swissler, T., Torres, O., Labow, G., Byerly, W., and Cebula, R. P.: Nimbus-7 Total Ozone Mapping Spectrometer (TOMS) data products user's guide, NASA Reference Publication, 1996.

McPeters, R. D., Bhartia, P. K., Krueger, A. J., Herman, J. R., Wellemeyer, C. G., Seftor, C. J., Jaross, G., Torres, O., Moy, L., Labow, G., Byerly, W., Taylor, S. L., Swissler, T., and Cebula, R. P.: Earth Probe Total Ozone Mapping Spectrometer (TOMS) data product user's guide, NASA Reference Publication, 1998.

McPeters, R. D. and Labow, G. J.: An assessment of the accuracy of 14.5 years of Nimbus-7 TOMS version-7 ozone data by comparison with the Dobson network, Geophys. Res. Lett., 23, 36953698, 1996.

Newchurch, M. J., Liu, X., Kim, J. H., and Bhartia, P. K.: On the accuracy of TOMS retrievals over tropical cloudy regions, J. Geophys. Res., 106, 32 325-32 326, 2001.

Newchurch, M. J., Sun, D., Kim, J. H., and Liu, X.: Tropical tropospheric ozone derived using Clear-Cloudy Pairs (CCP) of TOMS measurements, Atmos. Chem. Phys., 3, 683-695, 2003.

Olsen, M. A and Stanford, J. L.: Evidence of stratosphere-totroposphere transport within a mesoscale model and TOMS total ozone, J. Geophys. Res., 106, 27 323-27 334, 2001.

Pfister, G., Baumgartner, D., Maderbacher, R., and Putz, E.: Aircraft measurements of photolysis rate coefficients for ozone and nitrogen dioxide under cloudy conditions, Atmos. Environ., 34, 4019-4029, 2000.

Poulida, O., Dickerson, R. R., and Heymsfield, A.: Stratospheretroposphere exchange in a mid-latitude mesoscale convective complex 1. Observations, J. Geophys. Res.: 101, 6823-6836, 1996.

Ramanathan, V., Cess, R. D., Harrison, E. F., Minnis, P., Barkstrom, B. R., Ahmad, E., and Hartmann, D.: Cloud-radiative forcing and climate: Results from the Earth radiation budget experiment, Science, 243, 57-63, 1989.

Rossow, W. B., Walker, A. W., Beuschel, D. E., and Roiter, M. D.: International Satellite Cloud Climatology Project (ISCCP) documentation of new cloud dataset, pp. 737, WMO/TD, Geneva, 1996.
Rossow, W. B. and Schiffer, R. A.: ISCCP cloud data products, Bull. Am. Meteorol. Soc., 72, 2-20, 1991.

Salby, M. L. and Callaghan, P. F.: Fluctuations of total ozone and their relationship to stratospheric air motions, J. Geophys. Res., 98, 2715-2727, 1993.

Seinfeld, J. H. and Pandis, S. N.: Atmospheric chemistry and physics, John Wiley \& Sons, pp. 193-198, 1997.

Stanford, J. L., Ziemke, J. R., McPeters, R. D., Krueger, A. J., and Bhartia, P. K.: Spectral analyses, climatology, and interannual variability of Nimbus-7 TOMS version 6 total column ozone, Bull. Am. Meteorol. Soc., 77, 353-357, 1996.

Stowe, L. L., Yeh, H. Y. M., Eck, T. F., Wellemeyer, C. G., Kyle, H. L., and the Nimbus-7 Cloud Data Processing Team: Nimbus7 global cloud climatology. Part II: First year results, J Climate, 671-709, 1989.

Thompson, A. M., McNamara, D. P., Pickering, K. E., and McPeters, R. D.: Effect of marine stratocumulus on TOMS ozone, J. Geophys. Res., 98, 23 051-23 057, 1993.

Thompson, A. M., Pickering, K. E., McNamara, D. P., Schoeberl, M. R., Hudson, R. D., Kim, J. H., Browell, E. V., Kirchhoff, V. W. J. H., and Nganga, D.: Where did tropospheric ozone over southern Africa and the tropical Atlantic come from in October 1992? Insights from TOMS, GTE TRACE A, and SAFARI 1992, J. Geophys. Res., 101, 24 251-24 278, 1996.

Thompson, A. M., Oltmans, S. J., Schmidlin, F. J., Logan, J. A., Fujiwara, M., Kirchhoff, V. W. J. H., Posny, F., Coetzee, G. J. R., Hoegger, B., Kawakami, S., Ogawa, T., Johnson, B. J., Vmel, H., and Labow, G.: The 1998-2000 SHADOZ (Southern Hemisphere Additional Ozonesondes) tropical ozone climatology. 1. Comparison with TOMS and Ground-based Measurements, J. Geophys. Res., 108, 8238, doi:10.1029/2001JD000967, 2003.

Torres, O. and Bhartia, P. K.: Effect of stratospheric aerosol on ozone profile from BUV measurements, Geophys. Res. Lett., 22, 235-238, 1995.

Torres, O. and Bhartia, P. K.: Impact of tropospheric aerosol absorption on ozone retrieval from backscattered ultraviolet measurements, J. Geophys. Res., 104, 21 569-21 577, 1999.

Vaughan, G. and Price, J. D.: On the relationship between total ozone and meteorology, Q. J. R. Meteorol. Soc., 117, 12811298, 1991.

Wang, P.-H., Minnis, P., McCormick, M. P., Kent, G. S., and Skeens, K. M.: A 6-year climatology of cloud occurrence frequency from Stratospheric Aerosol and Gas Experiment II observations (1985-1990), J. Geophys. Res., 101, 29407-29429, 1996.

WMO: Scientific Assessment of Ozone Depletion: 1998, pp. 4.16, NASA, NOAA, UNEP, WMO, EC, Geneva, 1998.

Ziemke, J. R., Chandra, S., and Bhartia, P. K.: Two new methods for deriving tropospheric column ozone from TOMS measurements: Assimilated UARS MLS/HALOE and convective-cloud differential techniques, J. Geophys. Res., 103, 22 115-22 127, 1998.

Ziemke, J. R., Chandra, S., and Bhartia, P. K.: A new NASA data product: Tropospheric and stratospheric column ozone in the tropics derived from TOMS measurements, Bull. Amer. Meteorol. Soc., 580-583, 2000

Ziemke, J. R. and Stanford, J. L.: Kelvin waves in total column ozone, Geophys. Res. Lett., 21, 105-108, 1994. 